James Madison University JMU Scholarly Commons

Masters Theses

The Graduate School

Spring 2016

\title{
Effect of distance caregiver coaching on functional skills of a child with traumatic brain injury
}

Michelle R. Witt

James Madison University

Follow this and additional works at: https://commons.lib.jmu.edu/master201019

Part of the Applied Behavior Analysis Commons

\section{Recommended Citation}

Witt, Michelle R., "Effect of distance caregiver coaching on functional skills of a child with traumatic brain injury" (2016). Masters Theses. 95.

https://commons.lib.jmu.edu/master201019/95

This Thesis is brought to you for free and open access by the The Graduate School at JMU Scholarly Commons. It has been accepted for inclusion in Masters Theses by an authorized administrator of JMU Scholarly Commons. For more information, please contact dc_admin@jmu.edu. 


\title{
Effect of Distance Caregiver Coaching on Functional Skills \\ Of a Child with Traumatic Brain Injury
}

\section{Michelle Witt}

A thesis submitted to the Graduate Faculty of

\section{JAMES MADISON UNIVERSITY}

\author{
In \\ Partial Fulfillment of the Requirements \\ for the degree of \\ Master of Arts \\ Psychological Sciences, Applied Behavior Analysis Concentration
}

May 2016

FACULTY COMMITTEE:

Committee Chair: Trevor Stokes, Ph.D.

Committee Members/ Readers:

Barry Parsonson, Ph.D.

Carol Dudding, Ph.D. 


\section{Dedication}

I dedicate this thesis to my family and friends. I dedicate this thesis to my husband Greg for supporting me and our boys while I changed directions. I dedicate this to my children, Adam and Griffin, for providing me the inspiration to make a change and to continue to learn. I also extend a special thank you to my parents who never stop believing in me and encouraging me to set and reach new goals. To my friends who have supported me through this process, I also thank you. Your support and words of encouragement mean more than you know. 


\section{Acknowledgements}

I would like to express my thanks and gratitude to Dr. Trevor Stokes for providing me the opportunity to pursue a Master's degree. His quiet and persistent encouragement, coupled with his kind and ever-positive guidance throughout this endeavor, are most sincerely appreciated. I would also like to extend my gratitude to Dr. Barry Parsonson and Dr. Carol Dudding for their thoughtful and collaborative efforts in this process as members of my thesis committee.

Thank you also to Ana Barkaia for paving the way with Intercontinental Coaching. You set the bar very high, and I hope that I come close to your mark. Thank you also to Leslie Brittain, Melissa Grant and Claire Gallagher for your most excellent data analyzing.

I also thank the members of the Board and staff of Crossroads to Brain Injury Recovery for allowing me the space and providing me the support to pursue this degree while working for the organization. It is because of those affected by brain injury that I chose to learn more - so that I may someday be better able to help others. 


\section{Table of Contents}

Dedication...................................................................... ii

Acknowledgements...................................................... ii

List of Figures............................................................... vi

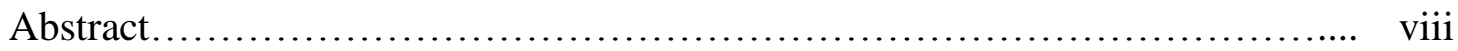

Literature Review........................................................... 1

Acquired Brain Injury .......................................... 1

Behavioral Changes After Brain Injury................................. 2

Pediatric Brain Injury........................................... 3

Brain Injury and Applied Behavior Analysis........................... 4

Coaching and Brain Injury Rehabilitation............................. 6

Access to Services and Telehealth.................................. 14

Applied Behavior Analysis, Coaching and Telehealth................... 15

Present Study ................................................. 17

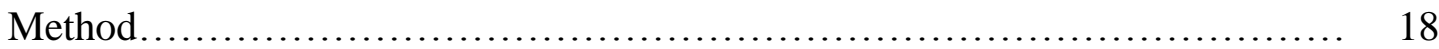

Confidentiality and Human Subjects Research....................... 19

Participants................................................... 20

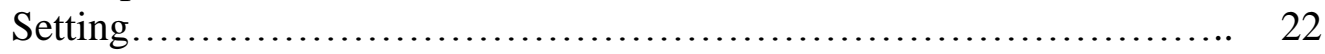

Independent Variable.............................................. 22

Dependent Variables............................................. 23

Caregiver Behaviors......................................... 22

Client Behaviors........................................ 23

Coaching Behaviors....................................... 27

Data Collection.................................................. 32

Caregiver Behaviors........................................ 34

Client Behaviors.......................................... 34

Coaching Behaviors....................................... 36

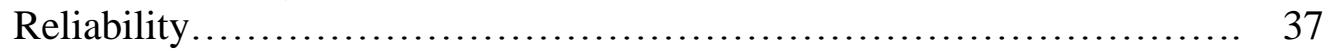

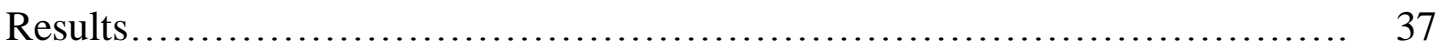

Client Behaviors................................................. 39

Caregiver Behaviors.............................................. 39

Coaching Behaviors............................................... 39

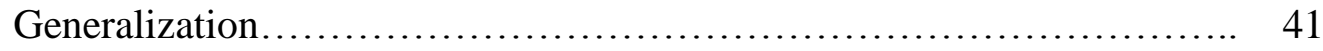

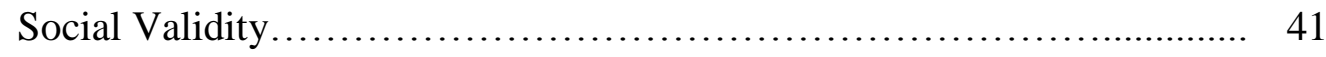


Discussion.

Figures................................................................ 46

Appendices....................................................... 50

Client Data Sheet - Brush Teeth................................. 50

Client Data Sheet - Write Name................................. 51

Client Data Sheet - Tie Shoe..................................... 52

Caregiver Data Skills Data Sheet................................. 53

Coaching Data Sheet.......................................... 54

Social Validity Questionnaire ................................. 55

References.............................................................. 56 


\section{List of Figures}

Figure 1. Client Functional Task Completion............................46

Figure 2. Effect of Distance Coaching on Caregiver Skills................47

Figure 3. Rate of Caregiver Prompting Across Client Functional Tasks.....48

Figure 4. Rate of Coaching of Comments Across Client Tasks.............49 


\begin{abstract}
Brain injury is a major public health concern affecting nearly 5 million Americans annually with a cost exceeding $\$ 60$ billion in the United States. Acquired and traumatic brain injuries cause physical, cognitive and social deficits resulting in behavioral, affective, cognitive, and physical changes. Though the biomechanical injury may be the initial source of the behavioral changes, environmental factors frequently contribute to maintaining maladaptive behaviors. Behavioral and affective changes in the person with a brain injury are frequently cited as the most distressing issues for caregivers, and their need for education and training is well documented. Interactions between caregivers and persons with brain injury may play a critical role in the rehabilitation process, and coaching caregivers may decrease unwanted behaviors exhibited by the person with the brain injury and foster more positive functional outcomes for the individual.

This study utilized a multiple probe, multiple baseline across behaviors, singlecase research design and examined the effects of caregiver behaviors on skill acquisition by a child with a traumatic brain injury. The caregiver-client dyad in this study was a mother and her 10-year-old adopted child. The researcher coached the caregiver using distance technology. Coaching consisted of in vivo feedback on the caregiver's use of general behavior analytic skills, such as use of effective prompting and positive social consequences, while engaging with the child with a brain injury. Improvements in the client's independent task completion across three functional tasks were observed, which correlated with changes in the caregiver's skills following distance coaching.
\end{abstract}




\section{Literature Review}

\section{Acquired Brain Injury}

Acquired brain injury (ABI) is a broad term used to define any injury or insult to the brain acquired after birth (non-congenital) and that is not hereditary or degenerative in nature (i.e., strokes, aneurysms, metabolic events, hypoxic events such as neardrownings or those caused by cardiac arrest) (Lash, 2007). Traumatic brain injury (TBI) is a type of $\mathrm{ABI}$ that results from some external force being exerted on the brain. Examples of sources of TBI include motor vehicle accidents, falls, gunshot wounds, assaults, sports accidents, and struck by/against events (Lash, 2005; Kraus \& Chu, 2005). According to the Centers for Disease Control's (CDC) 2015 Report to Congress on Traumatic Brain Injury, incidence and prevalence rates of TBI in the United States indicate that 1.5 million Americans sustain a traumatic brain injury annually. With more than 5 million Americans affected by brain injury, the CDC estimates the cost of brain injury exceeds $\$ 60$ billion in the United States. Brain injuries are usually classified as mild, moderate or severe. The vast majority $(80 \%)$ of injuries fall in the "mild" range, with between $10-30 \%$ in the "moderate" range, and between $5-25 \%$ falling in the "severe" range (Lash, 2007).

Brain injury is a leading public health concern, according to the International Brain Injury Association, and research is needed in the areas of prevention, medical treatment and therapeutic interventions. The 2015 CDC Report also states "the public health burden of TBI is substantial" and urges those in public health, research and practice to develop better strategies to reduce this burden. Brain injury is the second most prevalent injury and disability in the United States, and the leading cause of mortality and morbidity in children. Increasingly, brain injury is being conceptualized as a chronic 
disease versus a medical event due to the fact that many individuals experience permanent changes in functioning, may require long-term specialized care and supervision, and may be faced with reduced life expectancy (Masel and DeWitt, 2010). The neuropsychological sequelae of brain injury includes an array of cognitive changes such as memory loss, difficulty sequencing and organizing, deficits in attention and concentration, impaired judgment and decision making; physical changes such as fatigue, headache, weakness and paralysis, changes in vision and hearing, seizures, and neuroendocrine changes; and behavioral and affective changes such as aggression, agitation, impulsivity, depression and anxiety (Wood \&Alderman, 2011; Masel \& DeWitt, 2010; Corrigan \& Bach, 2005; Jacobs, 2010, Lash, 2007).

\section{Behavioral Changes after Brain Injury}

Persisting behavioral issues following brain injury limit individuals' engagement in homes, schools and communities following brain injury and can cause permanent, lifelong changes in an individual's functioning (Lash et al, 2007; Jacobs, 2010; Corrigan \& Back, 2005; Feeney, 2010; Masel \&DeWitt, 2010). Some behavioral difficulties experienced by persons with brain injury are a direct result of the injury such as impaired inhibition or difficulties with initiation, memory and concentration (Feeney, 2010). Some initially challenging behaviors may be produced in reaction to rehabilitation activities

(i.e., physical therapy, occupational therapy) that individuals find aversive which produce escape and avoidance behaviors such as verbal and physical aggression (Corrigan \& Bach, 2005; Mozzoni \& Hartnedy, 2000). Whether biomechanically-induced or environmentally-maintained, persons with brain injury frequently exhibit challenging behaviors. In 2006, the National Association of State Head Injury Administrators 
(NASHIA) released a report, Neurobehavioral Issues of Traumatic Brain Injury: An Introduction, in which they concluded:

Social consequences of mild, moderate, and severe TBI are many and serious, including increased risk of suicide, divorce, chronic unemployment, economic strain, and substance abuse. These consequences are tragic to individuals and families and place additional burdens on social service agencies, law enforcement, and the courts. As individuals with TBI attempt to resume their usual daily activities, the environment places increasing demands on them, uncovering additional psychosocial consequences. (p.8)

Further, changes in an individual's behavior and personality (affective changes) have been cited as the most distressing aspects of brain injury as reported by caregivers and family members, thereby increasing their need for continued, long-term education and support (Junque, Bruna \& Mataro, 1997; Sherer et al, 2015). The importance of addressing the long-term needs of caregivers and families, including addressing the emotional reactions, is critical and well documented (Hoofien, Gilboa, Vakil \& Donovick, 2001). It is also important to note that caregiver and family needs change over time and greatly impact quality of life (Kolakowsky-Hayner, Miner \& Kreutzer, 2001).

\section{Pediatric Brain Injury}

The CDC reports the highest rates of TBI occur among young children under the age of 4 , with falls being the leading cause of TBI in children overall. The CDC also indicates unintentional injury is the leading cause of death in young children, with TBI being the most prevalent source of injury. However, Keenan and colleagues (2003) found that " $80 \%$ of deaths from head trauma in infants and children younger than 2 years were 
from inflicted injuries" (p. 621). Billmore and Myers (1985) found that " $64 \%$ of all head injuries" and " $95 \%$ of serious or life-threatening head injuries" in children less than 2 years of age were the result of abuse (p.341). Peterson and colleagues (2014) described infant abuse (e.g., shaken baby syndrome) as "assaults on infants and young children that include violent shaking and blunt impact" (p. 92) and noted the effects of shaken baby syndrome can be severe with more than two-thirds resulting in significant physical, behavioral and neurological impairments.

Recent research indicates that injury sustained at a young age (i.e., under age 5) predicts poorer outcomes and may lead to long-term deficits that may even get worse as the child ages (Potter et al, 2001; Garcia, Hungerford, \& Bagner, 2014). Even though a child may "look well" after sustaining a brain injury, Lash and associates (2007) note that "more serious cognitive and behavioral problems may emerge as the child grows" (p. 108). Garcia and colleagues note "externalizing behavior problems are the most common and persistent negative outcome following early childhood TBI” (p. 392).

\section{Brain Injury and Applied Behavioral Analysis}

Applied Behavior Analysis (ABA) has been used widely in the treatment of behavioral difficulties following brain injury. Heinicke and Carr (2014) conducted a meta-analysis of applied behavior analysis in acquired brain injury rehabilitation and found more than 1400 articles related to their search. Approximately 60 percent of the studies focused on behavior reduction strategies, while only $37.4 \%$ focused on skill acquisition strategies. The authors note that interventions targeted a wide range of behaviors, and that when a functional behavior analysis (FBA) was used in a study, the primary function of the behaviors was noted to be escape. The authors also note that $70 \%$ 
of behavior reduction studies reported no FBA prior to intervention. The majority (64\%) of studies in the analysis focused on adults, and $81.5 \%$ of interventions were implemented in naturalistic settings.

The field of brain injury rehabilitation has used applied behavior analysis as a model for intervention but in a more limited fashion (mainly in in-patient rehabilitation settings) due to a number of perceived constraints with utilizing operant learning principles. Such perceived constraints include issues with impaired memory that affect the individual's ability to learn from consequences; deficits in motivation that affect the value of reinforcers; information processing deficits that make associative learning difficult; and difficulty generalizing from one situation to another (Wood \& Alderman, 2011; Ylvisaker, Turkstra \& Coelho, 2005). However, environmental factors are frequently cited as the cause and maintenance of challenging behaviors following brain injury (Corrigan \& Bach, 2005; Lash, 2007; Wood \& Alderman, 2011).

In refuting claims that behavior analytic interventions are less than efficacious in working with persons with brain injury due to the fact that the behaviors may be directly attributable to damaged neural structures in the brain, Wood and Alderman (2011) note many of the challenging behaviors exhibited by persons with brain injury may be reinforced by social attention provided by staff or caregivers and that these behavior patterns can be reversed "by ensuring social reinforcement is directed at desirable, rather than challenging behavior" (p. 208). For example, researchers used differential reinforcement of other behaviors (DRO) to reduce aggressive behaviors exhibited by a 28-year-old man with traumatic brain injury who resided in a specialized nursing facility (Hegel \& Ferguson, 2000). Further, differential reinforcement of other behavior (DRO) 
procedures have been employed to manage challenging behaviors in non-specialized applied settings, even when cases involve individuals who sustained brain injuries many years before (Wood \& Alderman, 2011). The authors also encouraged further use of single-case studies, specifically reversal or multiple-baseline designs to better meet the needs of persons served, as well as to educate practitioners on the efficacy of applied, operant interventions.

A theoretical basis for Wood and Alderman's call for the use of differential reinforcement procedures to ensure social reinforcement of desirable behaviors may be found in studies involving the matching law. Herrnstein (1970) determined through a series of experiments of reinforcement on concurrent variable-interval schedules that the rate of responding matches the rate of reinforcement received. Herrnstein went on to conclude that all behavior is essentially choice behavior. Even when it appears that only a single reinforcement schedule is devised, the individual may choose to do anything other than what produces reinforcement from the said schedule. McDowell (1988) provided an overview of how the matching law can be used in applied settings, citing a number of studies utilizing DRO to demonstrate. Altering the ratio of reinforcement received for desirable versus non-desirable behavior in any given setting can have broad effects.

\section{Coaching and Brain Injury Rehabilitation}

In its publication, The Essential Brain Injury Guide, the Brain Injury Association of America notes behavior can change following brain injury and that environmental influences too often "decrease adaptive behaviors and/or strengthen unwanted behaviors" (Lash, 2007, p. 97). In addition to affecting the individual, brain injury affects the family system and community as well (Lash, 2007). Interactions between persons with brain 
injury and others (e.g., teachers, parents, caregivers) can frequently become negative. For example, Wood and Alderman (2011) describe a downward spiral of behavior produced and maintained by social reinforcement as when an individual with a brain injury may engage in aggressive or other undesirable behaviors to escape rehabilitation that may be perceived as aversive. Staff and family members may quickly learn to avoid the individual with the brain injury due to the behaviors, which then leads to a situation of social isolation. Eventually, the only social interactions the individual may obtain are in response to the aggressive or otherwise undesirable behaviors, which becomes reinforcing. This negative interaction style is not unique to brain injury, and much can be learned from a review of the literature extending across populations and settings (i.e., disabilities, rehabilitation and education). Training parents, caregivers, teachers and staff is an integral part to improved interactions - with persons with brain injury and beyond.

A broad search of peer reviewed journal articles for terms including training and coaching for staff, teachers, parents, and caregivers across environments such as homes, schools and other community settings returns numerous single case design studies. Upon closer examination of the designs with an emphasis on coaching or training, research can be broadly divided between those studies focusing more on procedural fidelity and specific training protocols versus more generalized training on use of behavior analytic principles. The focus of this literature review is primarily on the research designs used in training more generalized behavior analytic skills.

The rationale for focusing on coaching and training of the appropriate use of behavior analytic techniques can be found in reviewing the literature, particularly those techniques focused on appropriate use of social contingencies. Stokes (1992) noted "the 
absence of a socially competent repertoire may be characterized by a dysfunctional combination of reciprocity and coercion within interactions" (p.430) and stresses developing technologies for teaching generalization and discrimination as a primary focus of lasting behavior change. Gianoumis and Sturmey (2012) conducted a review of the literature to assess generalization procedures utilized in training programs designed for persons who work with individuals with developmental disabilities. The authors reviewed the basic strategies one may employ to program generalization as outlined by Stokes and Baer (1977), and they found that the "most prevalent generalization procedures were use of common stimuli, followed by using sufficient exemplars and mediated generalization" (p. 620). A number of studies involving training and coaching of teachers, support staff, caregivers and parents incorporate these elements.

Rather than a specific training protocol, Parsonson, Baer and Baer (1974) suggested developing "techniques to teach, quickly, family or staff to use their inevitable social contingencies in a generalized correct manner" (p. 427). The reasons cited for this approach include the fact that social contingencies are "economical, natural, and relevant" (Parsonson, Baer \& Baer, 1974, p. 427). Stokes and Osnes (1989) noted that "focused training frequently has focused effects" and called for more generalized training, particularly in the area of attending to appropriate behaviors under development (p. 344).

Developing observation skills in order to attend to those behaviors may be critical, and coaching teachers, parents and caregivers has emerged as an effective method. Herbert and Baer (1972) found "knowledge of performance to be effective in modifying adult behaviors" (p. 148) in a study focused on training parents to self-record 
attending to their children's appropriate behavior. The researchers note that the proportion of attending to appropriate versus inappropriate behaviors resulted in an increase in appropriate child behaviors. Other early studies on the correct use of generalized social contingencies were conducted in preschool class settings and focused on providing coaching and feedback to teachers (Cooper, Thomson \& Baer, 1970; Parsonson, Baer \& Baer, 1974). Cooper et al used a multiple baseline across participants design to demonstrate the effectiveness of feedback on preschool teachers' attending behavior. The researchers defined "appropriate" and "disruptive" child responses as well as teacher "attending behavior," and they provided specific feedback regarding attending to appropriate child responses.

Koegel, Russo and Rincover (1977) conducted a "modified multi-response baseline" study to assess and train teachers in working with children with autism. Teachers were coached and trained on the use of more generalized behavior modification procedures such as correct use of prompts, shaping and consequences. The teachers were presented with essentially novel tasks to teach the children throughout the study, and the researchers found that coaching teachers on more generalized strategies produced learning across tasks. Rather than learning to teach a specific skill to the children, teachers learned skills to promote learning in general.

In another study by Koegel, Glahn, and Niemninen (1978), the researchers conducted a component analysis of generalization of parent training. Similarly, parents were trained on teaching specific skills in one phase and more generalized procedures that could be used in across a variety of skills or behaviors in another. The researchers again found that more generalized training on both antecedent and consequence strategies 
such as use of discrete trial; appropriate presentation of discriminative stimuli, and appropriate use of prompts, fading and consequence strategies produced durable and more generalized results that parents could employ with novel tasks and situations. Sanders and Glynn (1981) utilized a similar approach in their study on training parents as behavior change agents. The authors note that "evidence from the parent training field indicates that parents do not necessarily apply their skills to other untreated problem behaviors, other siblings, new settings, or when therapist contact terminates" (p. 223). The study utilized similar coaching and parent training interventions and also included self-monitoring which produced further increases in generalization across settings, including community settings.

Crimmins et al. (1984) utilized bug-in-ear coaching to improve parent-child interactions. Training focused on increasing positive comments, positive physical touch and appropriate use of contingencies. The training took place in a clinic setting, and the researchers conducted home probes for generalization. More recent studies that utilized a similar approach and multiple baseline across participants design include studies on Parent-Child Interaction Therapy (PCIT) and Teacher-Child Interaction Training (Choate, Pincus, Eyberg, \& Barlow, 2005; Naik-Polan and Budd, 2008; Lyon et al, 2009). PCIT and TCIT are both models that emphasize coaching parents and teachers on the use of appropriate social contingencies to increase positive interactions and decrease problem behaviors in children. Specifically, both models focus on coaching teachers and parents to use what the authors of PCIT coined as "PRIDE" skills (Praise, Reflect, Imitate, Describe, Enjoy). 
Shanley and Niec (2010) conducted a study that compared parents' skill acquisition via coaching versus non-coaching in a PCIT-style intervention. The researchers note that the specific mechanisms at work in PCIT style interventions are likely a combination of modeling, shaping, contingent reinforcement and extinction procedures, and that the coaching, particularly responsive versus directive coaching, is the key element in skill acquisition, as compared to feedback or didactic training components (Shanley \& Niec, 2010; Barnett et al, 2015).

In application to brain injury specifically, the American Academy for the Certification of Brain Injury Specialists calls for a focus on "Active Treatment Interaction," the component parts of which are five basic principles emphasizing broader use of appropriate social contingencies and categorized as - Positive, Early, All, Reinforce, Look and coined as "PEARL" (McMorrow, 2005). For example, in Guerico and Dixon (2011) trained staff of several group homes for persons with brain injury on the appropriate use of social contingencies by applying the concept of PEARL as set forth by McMorrow (2005). The researchers also studied residents' productivity and engagement as an outcome. Another aspect of this study that was unique was the authors' inclusion of a "happiness index" for residents that provided a measure of social validity.

In terms of pediatric brain injury, a number of recent studies have stressed the impact of the social environment, particularly parenting styles, on long-term functional outcomes for children with TBI (Potter et al, 2011; Mickelwright, King, O’Toole, Henrich \& Floyd, 2012). In a study by Wade and colleagues, the researchers note "positive parenting behaviors, such as warm responsiveness and an absence of negativity, may reduce the adverse effects of severe TBI on child behaviors" (2011, p. 731). 
Interventions, such as parent training, designed to increase positive interactions between parents and children with brain injury are recommended.

A review of the literature for single case studies that focus on training and use of appropriate social contingencies in brain injury rehabilitation produces a number of studies for consideration. Mozzoni and Bailey (1996) conducted a study focused on improving training across disciplines in brain injury rehabilitation. The researchers provided training to rehabilitation staff on general behavior modification / learning techniques "such as prompting, task analysis, and reinforcement procedures" (p. 2). Transdisciplinary rehabilitation staff included representation from physical therapy, occupational therapy, recreational therapy, speech-language pathology, and nursing. The study included analysis of both changes in staff behavior and patient behaviors.

In a study conducted to assess the effectiveness of training brain injury rehabilitation therapists to use generalized teaching and interaction skills, Ducharme and Spencer (2001) found that using a "general case approach" and "performance-based training" to be the most effective and efficient means of teaching staff skills needed to work with individuals with a broad array of impairments. The training focused on both "teaching" and "interaction" skills related to providing clear instruction, effective use and timing of prompts, use of contingent social approval, as well as appropriate uses of reinforcement, extinction and a graduated approach. The authors' distinction between “teaching" and "interaction" skills provides a potential framework for conceptualizing interventions. Teaching skills were defined as those involving more specific skill sets such as activities of daily living (e.g., setting the table, washing one's hands); whereas, interaction skills were defined more generally as pro-social and anti-social behaviors 
"that required differential responding from the therapist" (Ducharme \& Spencer, 2001, p. 338). "General case training" was found to equate to training "multiple exemplars" in an earlier study (Ducharme \& Feldman, 1992, p. 165).

Though many single case studies were conducted in a rehabilitation treatment or other group residential facility, a number of studies were conducted in more applied, community-based settings such as participants' homes. Palmisano and Arco (2007) conducted a study in Australia on persons with brain injury and their caregivers. The study included multiple participant dyads and was conducted in participants' homes. The researchers conducted weekly home visits providing training and coaching to caregivers on identifying target behaviors, using task analysis and prompting, and collecting and recording data. One of the strengths of this study and a reason for its inclusion in this review is the social validity aspect. The researchers were intentional in their inclusion of assessing caregiver burden and the effects of involving caregivers in the process, from identifying and defining behaviors to data collection. Caregivers reported a better understanding of the function of the individuals' behavior and a subsequent reduction in burden.

Another study by Arco and Bishop (2009) utilized a multiple-baseline across behaviors design to assess the effectiveness of positive behavior support for parents of individuals with brain injury. The "multi-component" intervention focused on learning activities of daily living and included some coaching of caregivers in supporting both children and adults with brain injury in their home environments. In addition to decreased problem behaviors and increased engagement in activities of daily living, the authors also noted a broader finding that "family-driven and family-integrated interventions offer 
many advantages such as increased motivation for implementation, increased acceptability and durability and reduced staff costs" (p.307).

\section{Access to Services and Telehealth}

Persons with brain injury struggle to access services due to many factors such as co-occurring psychiatric issues and chronic health conditions, as well as cognitive and behavioral changes such as memory loss, difficulty organizing and sequencing, and impaired judgment and impulsivity (Sherer, et al, 2015; Rahman, Oliver, \& Alderman, 2010; Peters, Gluck \& McCormick, 1992). Other barriers persons with brain injury face when attempting to access services include systems barriers (e.g. dearth of providers with expertise in brain injury, funding) and geographic issues (e.g. rural geography, lack of transportation) (Meixner, O’Donoghue \& Witt, 2012; Sherer et al, 2002). In a 2014 report to Congress, the CDC noted "access to services may be limited for those in need due to cost, geographic restrictions, and insurance." The CDC report also advocates for developing service models that use alternative delivery methods, such as telemedicine, to expand and improve access to services. Improving and expanding the use of behavior analytic interventions, both directly and remotely via telehealth, may be an effective means of increasing access to services and improving outcomes for persons affected by brain injury.

Forduccy and colleagues (2003) advocate for telerehabilitation for persons with brain injury, particularly those in rural, underserved areas. The authors discuss health disparities apparent in rural communities, including inadequate access to health care and rehabilitation for persons with brain injury stating, "those who survive their trauma find only limited community-based rehabilitation resources" (p.104). In defense of their 
argument for increased telerehabilitation options, the authors present a case study of an individual who received tele-physical therapy while residing in a skilled nursing facility. In addition to living in a rural community, the individual was ten years post injury. The intervention proved successful in improving the individual's movements. Additionally, neuropsychological testing indicated improvements in other areas of functioning that the researchers attribute, at least partially, to increases in physical activity that activated neural networks.

Ricker and colleagues (2002) also advocate for telerehabilitation for persons with brain injury. The researchers conducted a needs assessment utilizing a survey. Results indicate that "there is a great interest in the possibility of accessing telerehabilitative services" particularly in regard to services that could assist with "memory, attention, problem solving and activities of daily living” (p. 242). Similarly, Schopp, Johnstone and Ried-Arndt (2005) advocate for telehealth to support local, rural behavioral health practitioners who may tend to be more "generalist" in nature and frequently confronted with a more diverse array of presenting conditions, particularly in regard to individuals with brain injury.

\section{Applied Behavior Analysis, Coaching and Telehealth}

A number of studies have demonstrated that distance coaching and training (i.e. performed via telehealth technologies) are effective in implementing behavioral assessments and interventions. For example, researchers assessed the effectiveness of distance ABA training program for parents of children with autism who reside in rural communities. The program (OASIS) is a manualized training program consisting of eight tutorials or modules that combines web-based tutorials plus distance coaching by a 
trained $\mathrm{ABA}$ professional. The topics of the modules range from information about autism to basic $\mathrm{ABA}$ principles (stimulus control and antecedent and consequence strategies) as well as teaching strategies (prompting, fading). The researchers found parents made "substantial gains" in skill acquisition (Heitzman-Powell, Buzhardt, Rusinko, \& Miller, 2013, p. 32).

Wacker et al (2013) utilized a nonconcurrent multiple baseline design to study functional communication training to reduce problem behaviors of children with autism (p. 35). The researchers coached parents on Functional Communication Training via telehealth conducted at a number of regional clinics. Later, Lee and colleagues (2014) produced guidelines for developing telehealth services for use in parent coaching interventions, specifically when used to conduct functional analyses and functional communication training in home settings.

Other studies have also demonstrated the effectiveness of telehealth in conducting functional assessments (FA) via distance technology. Frieder and colleagues (2009) conducted an FA remotely from a university clinic to a preschool classroom in a rural public school 100 miles from the university. The researchers combined teacher training conducted via telepresence technology, with on-site visits and remote coaching during implementation. School personnel conducted the FA with high fidelity. Barretto et al (2006) also conducted brief FA's remotely from a university clinic site to home community sites with success.

Barkaia, Stokes and Mikiashvili (2016) utilized a multiple-baseline across participants design to study the effects of distance coaching on therapists' use of positive social consequences to enhance the verbal behavior repertoires of children with autism. 
The study was unique in that coaching was conducted intercontinentially via Skype from the United States to the country of Georgia-Sakartvelo. The coach was in the U.S. and the therapists and children were in home settings in Georgia. Distance coaching was effective in improving therapists' skills as well as child outcomes. The study also helped pave the way for further development and expansion of ABA services in remote and un-served geographic areas.

\section{Present Study}

The purpose of this study was to examine the effectiveness of distance coaching on caregivers' use of appropriate, positive social consequences to improve functional skills of persons with brain injury. Additionally, the study evaluated the efficacy of telehealth technology in improving access to ABA services and supports in un-served and under-served geographic areas. Coaching was provided from a remote location in Virginia to a client-caregiver dyad in their home via VSee, a HIPAA-compliant, encrypted telehealth platform. Videoconferencing sessions were recorded from a screen capture software and downloaded to an encrypted hard-drive for data analysis.

Generalization and maintenance probes are planned following training and intervention. A questionnaire was be used to assess caregiver satisfaction with the results as a measure of social validity.

A review of the literature on coaching yielded a number of single subject designs, including $\mathrm{AB}$ designs with replication, multiple baseline across participants, and multiple baseline across behaviors. The focus of this study was to examine the effects of remote or distance coaching on caregivers' use of appropriate social contingencies. The study also examined the effects of the intervention on the acquisition of functional skills by persons 
with brain injury with whom the caregiver interacts. Because activities of daily living (e.g., dressing, bed making) often entail complex behavioral chains, a multiple probe design, similar to the design described by Horner and Baer (1978) was selected for this study. The design is similar to a multiple baseline across behaviors design except that a "probe" was conducted on each subsequent behavior chain during initial baseline of the first behavior condition. Once steady state responding was established in the initial baseline, caregiver training and coaching began for the initial client behavior. A "true" baseline was conducted just before the intervention on the subsequent behaviors in the multiple baselines. The multiple probe design avoids some "pitfalls of measurement" which may be encountered when using a traditional multiple baseline across behaviors design, such as those described by Cuvo (1979). For example, the research design allowed for probes of baseline performance without subjecting the participant(s) to repeated measures and potential reinforcement of incorrect responding.

\section{Method}

During the initial baseline and initial probes, the researcher observed caregiverclient interactions via distance technology. Specifically, the researcher used VSee, a HIPAA-compliant video-conferencing platform that is compatible across multiple devices (i.e., desktop computer, laptop computer, iPad/tablet, iPhone/Android). The researcher also used screen recording software to securely capture the video calls, which provided a permanent audio and video product from which data was analyzed. The researcher-coach obscured the web camera so that she was not visible to the participants; however, the caregiver received coaching comments through a Bluetooth headset that also kept the comments confidential to the caregiver alone. The researcher-coach provided only general evaluative comments to the caregiver during baseline. 
Once steady state responding was achieved during the initial baseline, intervention on the first client behavior began the following session. The intervention consisted of a brief training followed by in vivo caregiver coaching via distance technology. The researcher provided the caregiver with a handout that outlined both the target caregiver and client behaviors and their associated definitions. The didactic training focused on identifying and defining targeted caregiver behaviors, as well as a task analysis and specific teaching strategies for each identified client functional task. Caregiver coaching began following the training and consisted of in vivo feedback on each of the target behaviors discussed during training. The length of each session varied based on the client's ability to complete the task. The researcher-coach provided caregivers with brief feedback, including a general session evaluation, following each session. Feedback was provided both in vivo prior to and following each session, as well as by email (only de-identified evaluative statements).

\section{Confidentiality and Human Subjects Research}

The study was approved by James Madison University's Institutional Review Board as an extension of an earlier study using distance technology to coach therapists working with children with autism in the country of Georgia (Barkaia, Stokes \& Mikiashvili, 2016). Maintaining participant confidentiality was of utmost importance. Using distance technology can pose threats to confidentiality as sensitive information can be transferred digitally, making it vulnerable to interception. However, the researcher utilized a HIPAA-compliant, encrypted video-conferencing platform (e.g., VSee) to observe and provide coaching comments in this study. According to the VSee website, the platform's security protocol includes a number of features to ensure the safety of data 
transmission such as use of end-to-end FIPS 140-2 certified 256-bit Advanced

Encryption Standard. No servers, including VSee's servers, have access to the decryption keys, and no information is ever stored on VSee's servers. Each session was recorded using screen capture software (Icecream Apps Screen Recorder) and transferred to an encrypted, password-protected external hard drive. The hard drive was kept in a secure location in a locked filing cabinet while not in use (i.e., when used for confidential scoring by the researchers), as they contained identifiable information such as faces and names of the participants. After data analysis and dissemination are completed, the original data sheets and videotapes will be destroyed.

Prior to the initial observation, the researcher ensured the security of the wireless Internet connectivity in the client-caregiver home. The connectivity was WPA2 (Wi-Fi Protected Access) password protected, ensuring a secure connection. WPA2 access meets the Institute of Electrical and Electronics Engineers (IEEE) local area network specifications, and "provides enterprise and consumer Wi-Fi users with a high level of assurance that only authorized users can access their wireless networks" (Webopedia, 2016).

\section{Participants}

Participants in the study were a caregiver-client dyad who received services through a not-for-profit organization serving persons with brain injury in rural Virginia. The participants were identified through the non-profit where the primary researcher was employed. The caregiver-client dyad was a mother and her 10-year-old adoptive child. The child sustained a severe traumatic brain injury as a result of abuse (e.g. shaken baby) at the hands of his birth parent. The caregivers provided foster care services for the child 
for a number of years prior formally adopting him. In addition to his brain injury, the child, Alvin (pseudonym), was also diagnosed with a chromosomal deletion disorder. The results of Alvin's disorder and injury include memory impairment, speech and comprehension deficits, and other challenging behaviors likely maintained by environmental contingencies.

A functional behavioral assessment (FBA) was completed prior to the study as part of the client's regular service provision through the brain injury program and in conjunction with James Madison University's Baird Center for Attention and Learning Disabilities where he received additional behavioral assessment and intervention services prior to the study. The FBA included both indirect and direct assessment methods and were conducted at school, in the clinic, and in the client's home. Based on the FBA, the client's challenging behaviors at school included those maintained by escape and avoidance when presented with task demands. Specifically, client behaviors noted as concerns included whining, crying, physical and verbal aggression (kicking, screaming, throwing items and property destruction), general non-compliance, and self-injurious behaviors at the most extreme.

Though non-compliant and escape behaviors were noted to occur less at home, Alvin's parents were concerned with Alvin's difficulty with completing a number of functional and self-care tasks. They described Alvin as being prompt-dependent and in need of nearly continual supervision in order to complete basic activities of daily living (i.e., dressing, bathing, toileting). Additional family concerns centered on managing Alvin's inappropriate behaviors, particularly in public (i.e., being overly friendly with strangers; difficulty transitioning away from preferred activities). 


\section{Setting}

All sessions took place virtually with the researcher in a clinic, and the caregiverclient dyad home in their home. The primary researcher observed and coached the caregiver via telepresence technology. Specifically, the researcher utilized a HIPAAcompliant telepresence platform, VSee, to conduct distance observation and in vivo coaching. The researcher-coach trained the caregiver on the use of distance technology, including setting up the platform on an iPad that was owned by the family. The researcher also provided the caregiver with a Bluetooth headset and trained her on its use. The Bluetooth headset allowed the caregiver only to hear coaching comments. The researcher was not visible to the participants as the web camera was covered, which allowed for less distraction and more unobtrusive observation.

\section{Independent Variable}

Distance coaching on the caregiver's use of behavior analytic skills was the independent variable in this study. Distance coaching is a multi-component intervention that entails coaching and feedback on both generalized interaction skills, such as the use of prompt sequences and positive social consequences, as well as specific skill acquisition, such as task analysis and chaining. The primary researcher served as the caregiver coach, providing in vivo feedback utilizing telepresence technology.

\section{Dependent Variable(s)}

Three categories of dependent variables in this study were (1) the caregiver's use of behavior analytic skills; (2) the client's acquisition of functional skills; and (3) coaching behaviors. 
Caregiver behaviors. Targeted caregiver behaviors included behaviors in two general categories termed "Do Skills" and "Don't Skills." Caregiver "Do Skills" included effective use and timing of prompts combined with contingent social approval, as described by Ducharme and Spencer (2001). Prompt and command sequences were targeted to facilitate the caregiver's use of a clear discriminative stimulus. PCIT-style positive social consequences (Eyberg \& Funderburk, 2011) were used to shift the ratio of caregiver attention toward desired client behavior and "close the loop" when the client complied with a caregiver prompt or command (Studivant, 2015; Barkaia \& Stokes, 2015).

Specifically, caregiver "Do Skills" included the following:

1) Prompt and Command Sequences. The caregiver was instructed to use specific direct statements that were clear and concise when prompting the person with a brain injury to engage in a task or behavior. A command was defined as an initiating verbal statement that prompts the client to begin a task or a step of a task. A verbal prompt was defined as any clarifying statement, verbal cue, or verbal hint as to what the client's next action should be. Commands and verbal prompts should be clear and stated positively. The caregiver was also instructed to wait 5 seconds after providing a command or prompt. The caregiver was instructed to repeat the command or prompt after the 5-second wait if the client did not comply.

2) Use of least-to-most prompts. Caregivers were instructed to use least-to-most prompts beginning with verbal, then visual, then physical to ensure client task completion. Initially, the caregiver was instructed to begin with verbal commands 
or prompts, followed by a 5-second wait to ensure compliance prior to issuing another command or prompt. If the client attempted the task but was unsuccessful, the caregiver was instructed to use a visual prompt such as a gesture or modeling the desired behavior. A gesture was defined as including pointing, mouthing words silently, or indicating the desired physical movement. Modeling was defined as showing the client the desired behavior without physically touching. Following a 5-second wait, if the client was again unsuccessful in completing the task, the caregiver was instructed to use a physical prompt and provide only as much touch as needed to guide the client to complete the task.

3) Contingent use of positive social consequences. The caregiver was instructed to provide immediate positive social consequences for desired client behavior that included either compliance with a task command or prompt ("closing the loop"), as well as independent completion of a desired behavior or task. Immediate was defined as within 3 seconds of the client emitting the behavior. The caregiver was provided with training and feedback on use of positive social consequences in the form of a PCIT-style interaction (e.g., labeled and unlabeled praise, reflections, behavior descriptions, and positive physical touch) (Eyberg \& Funderburk, 2011).

a. Labeled praise was defined as any caregiver comment that included both praise and a specific statement regarding the behavior being praised (i.e., "I like how neatly you made your bed").

b. Unlabeled praise was defined as any positive statement made following appropriate client behavior (i.e., "Great job!”). 
c. A reflection was defined as any verbal response that imitated the verbal content of verbal response made by the person with a brain injury. An example of a reflection is when the client says, "I like my shirt," and the caregiver repeats, "You like your shirt."

d. A behavior description was defined as any statement describing the appropriate behavior of the person with the brain injury (i.e., "You made your bed!’).

e. Positive physical touch included any physical interaction intended to show approval such as high-fives, tickles, backrubs, hugs, touching the client's hand in a friendly way, etc.

4) Planned ignoring. Caregivers were instructed to use planned ignoring of minor protests (e.g. whining, complaining). Ignoring was defined as diverting eye gaze, showing no facial expression and avoiding contact with the client immediately following minor protests. The caregiver was then instructed to attend to the first appropriate client behavior.

5) Use of specific training skills. Caregivers were coached to use specific skills for teaching complex behaviors such as task analysis and backward chaining. Though these behaviors are not scored for caregivers, the behaviors are included as part of coaching comments.

Caregiver "Don't Skills" included the use of indirect commands and questions, as well as negative talk and negative touch. Specifically, "Don't Skills" were defined as:

1) Questions. Questions that were used as commands or prompts were also targeted for reduction. Questions were defined as essentially indirect 
commands that leave too many options from which the client may choose instead of the "correct" option. Questions also indicate that a choice is available, which may lead to increased non-compliance. Examples of questions include: "How about you change your clothes now?" or "Will you please brush your teeth?” Ending a statement with “Ok?” or with a general upward inflection in the voice was also considered a question and was targeted for reduction. Questions that were conversational in nature or asked in order to determine clarification were not included or scored.

2) Indirect commands. An indirect command was defined as any statement that is unclear as to who is being told to complete a task or what specific task is to be completed. Examples of indirect commands include: "It's time to set the table," "I wonder who left their shoes in the floor," or “"'Let's put on our shoes."

3) Incorrect timing. Incorrect timing is defined as any command or prompt (verbal, visual or physical) that is not followed by a 5-second wait prior to the caregiver issuing another prompt or command.

4) Negative talk. Negative talk was defined as any comment made by the caregiver that indicated displeasure or meant as a reprimand. Negative talk also includes sarcasm and criticism. Examples of negative talk include, "Uh-oh," "No," "Not like that," "Stop doing that," and "You're doing it wrong."

5) Negative touch. Negative touch included any physical touch that is rough or intended to show the caregiver's disapproval.

Coaching was provided until the caregiver met a predetermined criterion for performance which was defined as responding with a rate that met or exceeded five per 
minute for "Do Skills" and that was at or below 1.5 per minute for "Don't skills" across three consecutive sessions. Once the caregiver met performance criteria, coaching comments were faded based on whether caregivers continued to meet criterion. If performance began to fall below criterion, frequency of coaching comments were increased to ensure performance.

Client behaviors. Target behaviors of the persons with brain injury include functional skill acquisition such as self-care skills. Self-care behaviors may be broadly defined as activities of daily living and include such tasks as bathing, feeding, personal hygiene, dressing, meal preparation, housekeeping, etc.

The researcher observed the caregiver and client engaging in seven different functional skills tasks over 23 sessions prior to selecting the target behaviors for intervention. The seven behaviors included brushing teeth, dressing (putting on a shirt, socks and shoes, tying shoes), writing the client's first name, and setting the table for dinner. The behaviors selected for observation were based on the caregivers' reports of tasks that present on-going challenges in their lives, such as having to monitor and continually prompt the client in order for him to successfully complete the task. For example, during the initial behavioral interviewing, the father reported the client taking 1.5 hours to put on a shirt one morning and "playing in the water" when brushing his teeth for extended periods of time if not closely monitored. Both parents agreed that teaching the client to be more independent and self-sufficient is a major goal for them.

Three specific client target behaviors (brushing teeth, writing name and tying shoes) were selected after observation, and a task analysis was conducted for each client 
target behavior prior to intervention. Each step of each task was scored based on whether the client completed the step independently, with prompts or not at all.

Brush teeth. Brushing teeth was selected as the first client behavior. The client had tooth-brushing skills in his repertoire, but he required significant prompting to complete the steps. Also, brushing teeth offered an opportunity for the caregiver to practice the general behavior analytic skills (prompting and positive social consequences) prior to adding specific teaching skills such as chaining. The researcher-coach provided the caregiver with general adaptive strategies such as running the toothbrush and paste under water prior to brushing and prompting the client to use a circular motion when brushing.

The researcher conducted a task analysis of brushing teeth and provided an outline of the steps to the caregiver prior to implementation. Additionally, the researcher used a diagram of the outside and inside of a set of teeth to help track which steps were completed. The researcher also provided the diagram to the caregiver for reference purposes. The task analysis was similar to that used by Brown (2012) and included the following steps (some steps were combined as the client was fluent in some, but not all steps):

1. Get toothbrush and paste.

2. Open paste and put paste on brush.

3. Replace cap on paste.

4. Run brush under water to get paste wet.

5. Brush right side out for 5 seconds.

6. Brush left side out for 5 seconds. 
7. Brush front out for 5 seconds.

8. Brush inside top right for 5 seconds.

9. Brush inside top left for 5 seconds.

10. Brush inside top front for 5 seconds.

11. Brush inside bottom right for 5 seconds.

12. Brush inside bottom left for 5 seconds.

13. Brush inside bottom front for 5 seconds.

14. Brush tongue.

15. Rinse toothbrush.

16. Rinse mouth and wash face.

17. Wash out sink.

18. Turn water off.

19. Dry face and hands.

Write name. The second client behavior targeted for improvement was writing the client's first name. Writing his name was defined as when the client prints his first name independently. The first letter only will be capitalized. Each subsequent letter will be printed in lower case. Spacing between the letters will be no more than 1 finger (client's) width apart. The letters will be written in order and produce a recognizable word. Each section of an individual letter will be scored as a specific step. For example: the letter “A” would include three distinct steps: “/," “॥," and “-." The client's real name was used, so a true task analysis is not provided in this document to maintain confidentiality; however, the task analysis identified the task as containing 10 distinct steps. 
In addition to maintaining correct command/prompt sequences and positive social consequences, the researcher coached the caregiver on using fading to reduce the visual prompts as the client learned to write his name. During initial observations and baseline, the caregiver used full visual prompts of writing the client's name on a piece of paper for him to trace and copy. The researcher coaching the caregiver on how to fade the prompt by making the lines less prominent, to using dashed lines, to using a few dots, to using no visual prompt.

Tie shoes. The researcher observed during the initial observation period that the client could put his shoes on his own feet with some prompting; however he was unable to tie his shoes. Tying shoes was selected as the third client behavior, and it is the most complex of the three behaviors. In addition to maintaining the use of correct command/prompt sequences and contingent positive social consequences, the researcher coached the caregiver on the use of another specific teaching strategy. The researcher coached the caregiver on how to use chaining to link each discrete behavior of the task analysis into a continuous, complex behavior.

The initial task analysis, based on the steps the caregiver traditionally used to prompt the client to tie his shoes, involved the following steps (and these steps were used to score baseline responding):

1. Put shoe on foot.

2. Pull tongue and laces tight.

3. Cross the laces ("criss-cross").

4. Take 1 lace under the "criss-cross."

5. Pull tight. 
6. Make a loop in one lace ("bunny ear").

7. Wrap the other lace around the loop.

8. Push lace through the hole created by wrapping lace around the loop on the other.

9. Pull tight.

The researcher and the caregiver sought consultation with the client's occupational therapist regarding potential alternate methods for shoe tying that may be easier for the client due to some fine motor skills deficits. The task analysis of the steps conducted during coaching and intervention included many of the same initial steps but a few changes to the later steps. Given that the client was unable to complete the later steps in baseline, responding in both conditions was not affected by the change in task steps. The steps completed in intervention are as follows:

1. Put shoe on foot.

2. Pull tongue and laces tight.

3. Cross the laces ("criss-cross").

4. Take 1 lace under the criss-cross.

5. Pull tight.

6. Make a loop in one lace ("bunny ear").

7. Make another loop in the second lace (second "bunny ear").

8. Cross the bunny ears.

9. Push one loop (bunny ear) under the criss-cross

10. Pull tight. 
The addition of a single task step in the intervention changed the overall number of steps to be completed, thereby changing the percent per opportunity. This is noted in the discussion as a limitation.

Coaching behaviors. Coaching behaviors included in vivo feedback provided to the caregiver(s). Feedback included various forms of labeled praise for specific caregiver behaviors such as the use of appropriate prompts, use positive social consequences, closing the loop, and "higher order" evaluative statements (Barkaia, Stokes, \& Mikiashvili, 2016; Studivant, 2015; Barkaia \& Stokes, 2015). Coaching behaviors mirrored many caregiver behaviors as they were categorized also as "Do Skills" and "Don’t Skills."

Specifically, coaching behaviors in the "Do Skills" category consisted of:

1) Labeled praise 1 . The first category was scored whenever the coach provided the caregiver with labeled praise for using labeled praise, reflections, behavior descriptions and positive touch.

2) Labeled praise 2. This category was scored whenever the coach provided the caregiver with praise for any other positive, unlabeled praise, use of enthusiasm, and imitation.

3) Labeled praise 3. The third category of labeled praise was scored when the coach provided the caregiver with a positive evaluation for "closing the loop."

4) Labeled praise 4. The final category of labeled praise was scored when the coach provided the caregiver for appropriate and effective use of specific skills training (i.e., direct commands, prompt sequences, modeling, physical guidance, chaining, fading). 
5) Unlabeled praise. Unlabeled praise is any other general praise provided by the coach to the caregiver (i.e., "good job" or "great!").

6) Descriptive label. A descriptive label is defined as when the coach makes a statement regarding the behavior of the caregiver. It is similar to the "behavior description" in the caregiver target behaviors list. Descriptive labels may include describing exactly what the caregiver is doing such as "that was an indirect command" or "you are prompting him."

7) Direct command. A direct command is defined as when the coach tells the caregiver to engage in a specific behavior. Like the caregiver behaviors, a direct command is a simple, direct statement. For example, the coach may say, "describe what he is doing," or "tell him to put on his shirt."

8) Higher order. Higher order statements are general evaluative statements that the coach provides the caregiver such as feedback regarding timing and pacing or the interaction between the caregiver and client. Examples may be: "Your prompts are helping him complete the steps," "good timing," or "your interaction is positive and friendly."

Coaching "Don't Skills" include:

1) Indirect command. This is similar to the caregiver behavior by the same name. An indirect command is an ambiguous statement intended as a command or prompt. Questions by the coach are also considered indirect commands if they are used to prompt the caregiver. Examples include: "Could you be more specific?" or "Let's try having him brush in circles." 
2) Critical statement. A critical statement by the coach is similar to negative talk by the caregiver. For example, the coach tells the caregiver, "Stop using so many negatives," or "You're not prompting him correctly."

3) Incorrect statement. If the coach mislabels a caregiver target behavior, then it is considered an incorrect statement. For example, the coach praises the caregiver for using labeled praise when the caregiver used a behavior description. An incorrect statement is also scored if the coach praises a caregiver "don't skill."

\section{Data Collection}

Sessions were conducted via distance technology, and each session was video recorded using screen capture software to create a permanent product for data analysis. Data were analyzed in repeated measures across sessions and summarized in graph format using a computer and common spreadsheet software (e.g., Microsoft Excel). The primary researcher (and coach) and trained student researchers scored each videotaped session. Training consisted of didactic training on each behavior definition and practice sessions using the definitions and scoring rules. To increase fidelity, the student researchers assisted the primary researcher in defining and refining each behavior definition and scoring rule following practice sessions. The primary researcher ensured that each student researcher met mastery criteria on scoring which was at least $80 \%$ agreement on caregiver, client and coaching behaviors. The researcher provided a final, written version of the behavior definitions and scoring rules to each data collector.

Caregiver Behaviors. Each of the caregiver behaviors ("Do Skills" and "Don't Skills") were scored using event recording and a rate of correct responding was calculated for contingent positive social consequences (C-PSC), "Do Skills", and "Don't 
Skills." Rate was selected as the measure for the behaviors due to a number of practical considerations. The researcher examined the data a number of ways, including by percent per occurrence and by percent per opportunity, as well as frequency count. However, inspecting the data based on a percent per occurrence calculation revealed a pattern of responding that was misleading from actual observation. For example, the caregiver may respond with only a single positive social consequence in a single session that results in $100 \%$ per occurrence for contingent, positive social consequences, which is a misrepresentation of the intended change in responding.

Likewise, a percent per opportunity was explored, but based on the behavior definitions, too many opportunities to provide positive social consequences were identified to make this a practical approach. Additionally, because the duration of each session or observation varied so greatly both within and between behaviors, imposing a set observation time frame seemed difficult from a practical standpoint and eliminated a frequency or count as an option (as well as interval recording). For example, brushing teeth may only take five minutes to complete, whereas tying shoes may take 12 minutes and writing one's name may only take 2 minutes. Some behaviors may lend themselves to repeated trials within an observation session; however, others do not (e.g., brushing teeth), so setting a longer observation period may not be in the best interest of the individual. Further, setting a shorter observation period may have resulted in the client not having time to independently complete a task.

The researcher was able to calculate a rate of responding across caregiver and coaching behaviors that allowed for differing observation time frames. Rate was calculated by dividing the total number of responses by duration of the task to produce a 
frequency per minute of responding. Time to complete each task varied both within each task and between tasks, and the duration (in minutes) of each session was calculated based on the time stamps on each video recording. The rate of caregiver use of C-PSC was calculated by dividing the total number of contingent, positive social consequences by the duration of the session. Contingent was defined as occurring when the caregiver provided any positive social consequence immediately (within three seconds) following the client's compliance with a prompt or command. A contingent positive social consequence was also scored when the caregiver provided appropriate social consequence for a client's independent (i.e., unprompted) completion of a task step.

The rate of caregiver "Do Skills" was calculated by dividing the total number of correct command and prompt sequences, combined with the total number of positive social consequences, by the duration of the session (total count divided by time). Similarly, the rate of caregiver "Don't Skills" was calculated by dividing the total number of incorrect prompt sequences (questions, indirect commands, and prompts with incorrect timing) plus the total number of negative social consequences by the duration of the session (total count divided by time).

Client behaviors. Client behaviors were scored according to the number of steps of the specific behavior chain the individual completed per session. Each step was scored as having been completed independently, with prompting, or not at all. A percent of independent steps was calculated by dividing the number of correct steps completed independently by the total number of steps in the behavior chain and multiplied by 100 . The percent of tasks steps completed with prompting was calculated by dividing the number of prompted steps divided by the total number of steps in the task and multiplied 
by 100 . Lastly, the total number of task steps not completed at all was calculated by dividing the number of steps not completed in a task (either omitted or unable to complete) by the total number of steps in the task and multiplied by 100 .

Coaching behaviors. Coaching behaviors were scored utilizing event recording per session similar to caregiver behaviors. Each coaching "Do Skill” was tallied, as well as each coaching "Don't Skill.” A rate of coaching "Do Skills” was calculated by dividing the total number of "Do Skills" by the duration of each session (in minutes). The rate of "Don't Skills" was calculated the same way.

\section{Reliability}

The primary researcher scored all sessions. Additional researchers independently scored $30 \%$ of sessions in each baseline and intervention phase of the experiment in order to obtain inter-observer agreement (IOA). Total count IOA was determined for caregiver behaviors by dividing the smaller count of "Do Skills" by the larger count and multiplying by 100 to obtain a percent agreement. Total count IOA was also used for caregiver "Don't Skills" where the smaller count of "Don't Skills" was divided by the larger count and multiplied by 100 . IOA for caregiver behaviors was obtained across all baseline and intervention sessions across three target client behaviors ( 8 of 18 baseline and 4 of 15 intervention sessions or $36 \%$ of all sessions).

Agreement for caregiver "Do Skills" in baselines ranged from 81\% - 100\% for an average of $90 \%$ agreement. Agreement for caregiver "Don't Skills" ranged from $77 \%$ to $100 \%$ for an average of $90 \%$. Agreement for caregiver "Do Skills" during intervention sessions ranged from $85 \%$ to $97 \%$ for an average of $91 \%$ agreement. Agreement for 
caregiver "Don't Skills" during intervention ranged from $88-100 \%$ for an average of $93 \%$ agreement.

Exact agreement was used to calculate IOA for client behaviors. Specifically, each step in which both observers scored the same step as independent, prompted or not completed was scored as an agreement. The total number of agreements was divided by the total number of agreements plus disagreements for each step and multiplied by 100 . Reliability for the number of independent task steps completed for "Brush Teeth" was calculated for $40 \%$ of baseline sessions for an average of $85 \%$ agreement, and it was calculated for $27 \%$ of intervention sessions ( 3 of 11 to date) for an average of $93 \%$ agreement. Reliability for number of independent task steps completed for "Write Name" was calculated for $42 \%$ of baseline sessions for an average of $97 \%$ agreement, and it was calculated for $25 \%$ of intervention sessions ( 1 of 4 to date) at $100 \%$ agreement. Reliability for the number of steps completed independently for "Tie Shoes" was calculated for 50\% (3 of 6) of baseline sessions for an average of 93\% agreement. Reliability for coaching comments was calculated in the same fashion as caregiver behaviors. The smaller count of coaching "Do Skills" was divided by the larger count and multiplied by 100 . The same procedure was used to calculate coaching "Don't Skills" in which the smaller count of "Don't Skills" was divided by the larger count and multiplied by 100. Reliability for coaching "Do Skills" was obtained for 33\% (6 of 19 coaching sessions) for an average agreement of $91 \%$. Similarly, reliability for coaching “Don't Skills" was obtained for 335 (6 of 19 coaching sessions) for an average agreement of $100 \%$. 


\section{Results}

Client behaviors. Results indicate that distance coaching improved client functional skills across behaviors (Figure 1). Baseline responding was relatively stable for "Brush Teeth," though there was a slight upward trend. However, there was a clear change in the level of responding between baseline and intervention phases. No data points in the intervention phase fell below the highest baseline data point. During the baseline phase of "Brush Teeth," client independent task step completion averaged 35\%; whereas independent task step completion during intervention was $56 \%$.

The second client behavior, "Write Name," showed a similar result. A clear level change in responding from baseline to intervention was noted with client independent task step completion averaging $39 \%$ in baseline to $75 \%$ in intervention.

The third client behavior, "Tie Shoes," is less indicative of experimental control as a potential confound may have contributed to an increasing trend in the percent of independent task completion. Responding was stable at $22 \%$ independent task step completion for the first four baseline probes; however, a noticeable increase in independent task step completion was observable beginning with the fifth probe session. The researcher learned that the client was receiving outpatient Occupational Therapy services, and the Occupational Therapist had been working on the same functional task of learning to tie shoes. The researcher requested that the therapist hold off on teaching the skill to help reduce the impact of the confounding variable.

Caregiver behaviors. Results indicate that distance coaching was effective in increasing the caregiver's use of appropriate, positive social contingencies across three client target behaviors (Figure 2). The caregiver's use of contingent, positive social consequences during baseline for "Brush Teeth" was stable and at near-zero levels. After 
implementing coaching, the caregiver's use of contingent, positive social consequences steadily increased to a rate of nearly 4 per minute. Similarly, in the baseline behaviors of "Write Name" and "Tie Shoes," the caregiver's use of contingent, positive social consequences was also at an overall low level with a rate of less than 1 per minute. However, during coaching on the second baseline ("Write Name"), the caregiver's rate of contingent, positive social consequences increased significantly. Though there was a slight upward trend in responding during baseline, there was a clear level change from baseline to intervention.

Increases in the caregiver's "Do Skills" and decreases in the caregiver's "Don't Skills" are noted across two of the three client baseline behaviors, particularly during the intervention phases as compared to baseline phases.

Additionally, the rate of caregiver prompting was also analyzed (Figure 3). Overall rates of caregiver prompting steadily decreased over sessions, particularly as compared with the overall increasing trends in the rates of contingent, positive social consequences. The data may be indicative of the caregiver's use of more effective and efficient prompting.

Coaching behaviors. The rate of coaching "Do Skills" and the rate of coaching "Don't Skills" was examined (Figure 4). An observable and steady increasing trend in coaching "Do Skills" occurred in the first and second legs of the multiple baseline design. A decreasing trend in coaching "Don't Skills" across the two legs of the multiple baseline was also observed. 


\section{Generalization}

Some improvements in both caregiver and client responding were noted during the second and third baselines after intervention on the first baseline, which was to be expected given the experimental design.

\section{Social Validity}

The term social validity has to do with whether an intervention has value to society (i.e., individual, family, community), and addresses a key dimension (e.g., applied) of applied behavior analysis (Wolf, 1978; Baer, Wolf, \& Risley, 1968). The caregiver was interviewed prior to the beginning of the study to assess her interest and concerns. A questionnaire will be used following the study to assess the caregiver's perceptions regarding the results of the intervention such as whether she felt it was effective and whether she will use the skills in other settings. The questionnaire will also assess the caregiver's perceptions regarding the use of distance technology. A copy of the questionnaire is included as an attachment.

\section{Discussion}

A multiple probe, multiple baseline across behaviors design was used to demonstrate the effects of distance coaching on client functional skill acquisition. The number of probes in each baseline was varied to demonstrate experimental control achieved across behaviors. Five baseline sessions were conducted in the first leg of the multiple baseline, seven were conducted in the second, and at least eight will be conducted in the third. Overall, results indicated that distance coaching increased caregiver's use of appropriate behavior analytic skills such as effective prompting and positive social consequences. More importantly, the results indicated that distance 
coaching provided to the caregiver also had a positive impact on the client's functional outcomes.

A number of strengths and limitations are noted regarding this study. The changes in both client and caregiver responding between baseline and intervention phases across behaviors provides a demonstration of experimental control. Some generalization across baseline phases, particularly in regard to caregiver behaviors, was to be expected. This finding is consistent with the hypothesis that coaching and feedback on the use of generalized behavior analytic skills not only facilitates learning, but also lends itself to generalization to other behaviors. Though this may weaken experimental control, the effect has positive, practical implications as an effective clinical application. If a single intervention can produce positive changes across behaviors, then the intervention could prove to be both effective and efficient.

In addition to generalization across coached behaviors, probes of other nontrained client behaviors may indicate the caregiver utilized the skills taught during coaching. The researcher observed and recorded the client and caregiver engaging in a number of tasks prior to selecting the three target behaviors for the study. It would have been valuable to assess these behaviors at the end of the study.

The overall rate of caregiver prompting decreased while the percent of independent client task completion increased which may indicate an increase in prompting efficiency on the part of the caregiver. Another potential avenue to explore in future study or analysis of the data may include investigating which type of prompting (e.g. verbal, visual or physical) was the most effective for this client. 
A different design such as a multiple baseline across participants could provide a greater demonstration of experimental control. Additionally, this study involved a single caregiver-client dyad. Replicating the study with additional caregiver-client dyads could strengthen the demonstration of experimental control and should be considered a future direction for continued research, particularly in regard to how the techniques used in this study would need to be modified for older children, teens and adults. Replication would establish the generalizability of the current finding.

Other limitations to the study include potential generalization effects of repeated measures during the baseline phases. Even though a probe design was used which helped to ameliorate the effects of repeated practice on improving skills, instability in the baseline data required additional probes which could have contributed to increases in responding as well. As noted above, increases in client responding in the second and third baselines may also be a result of potential confounds. The researcher learned that the client was being taught the same or similar skills in other settings at approximately the same time as baseline data was being collected. Though the researcher was able to mitigate the effects of one confound, it is possible that the data still reflect learning as a result of interventions beyond those introduced in the study.

Caregivers were provided with a brief training prior to the coaching intervention. The training was limited to terms and concepts related to behaviors to be coached, and a future design may include a component analysis where training is one condition and coaching is a separate, subsequent condition. However, a review of the literature indicates that coaching is the key element in this type of multi-component intervention. Closer examination of specific coaching behaviors may be warranted in future studies, as 
the data suggest that the researcher-coach's behaviors were also being shaped through this process that essentially entails video self-modeling.

Similarly, in the current study, client could see himself on the iPad while the caregiver received coaching comments. The client watched attentively while he engaged in a task which may make video self-modeling an effective maintenance strategy. In a future study, short videos of the client performing each task independently could be developed from the recorded sessions. The researcher-coach could train the caregiver on how to use the videos with the client to promote maintenance of the new skills.

Another limitation of the study may stem from discerning whether training and coaching or the repeated practice of each self-care behavior produced the results. It is likely that training and coaching are the variables that produced the change as repetition of inaccurate responding is likely to lead to learning inaccurate responding. Further, the increase in client independent task completion may be the result of experiencing success in that achievement (e.g., completing steps of the task independently) has reinforcing value.

The technology used in this study presented both a strength and a weakness. The technology provides a way to observe interactions unobtrusively in client/caregiver homes. The researcher used low-cost, accessible technology that could be used by researchers and practitioners alike. However, connectivity was an issue at times, and jerky motions made observing certain behaviors difficult to see clearly. At other times, the behaviors would be off camera, so the researchers could not collect data on a particular, discrete step in a task. Continued research and use of the technology is 
recommended to refine the application. Overall, the technology proved to be useful and shows great promise for expanding ABA services to unserved or under-served areas.

Based on this research, recommendations for future study and practice include continued exploration of the effects caregiver-client interactions on client functional skill acquisition. If coaching caregivers to use general behavior analytic skills, such as effective prompting and positive social consequences, has positive effects on functional outcomes across age groups and injury severity, the implications for ABA services in the field of brain injury rehabilitation are significant. Further research on generalization of functional skills by persons with brain injury is also warranted. As demand for ABA services continues to grow, continued research on the use of distance technology as a viable mechanism for service delivery should be conducted. 
Figure 1.

\section{Client Functional Task Completion}

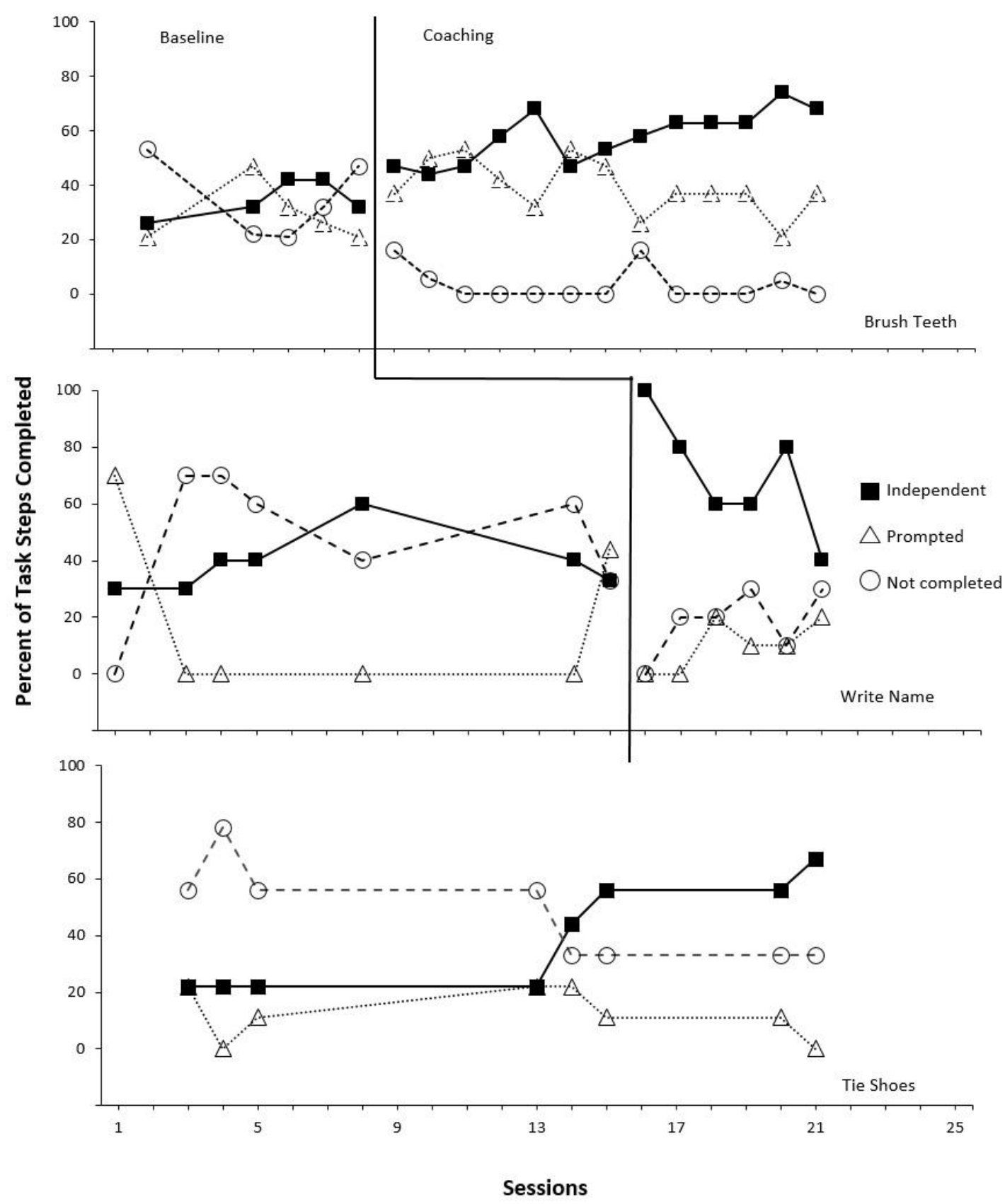

Figure 1 shows the percent of client functional task completion during baseline and intervention phases across three behaviors. A percent of steps completed independently, completed with prompting and not completed are shown. 
Figure 2.

\section{Effect of Distance Coaching on Caregiver Skills}

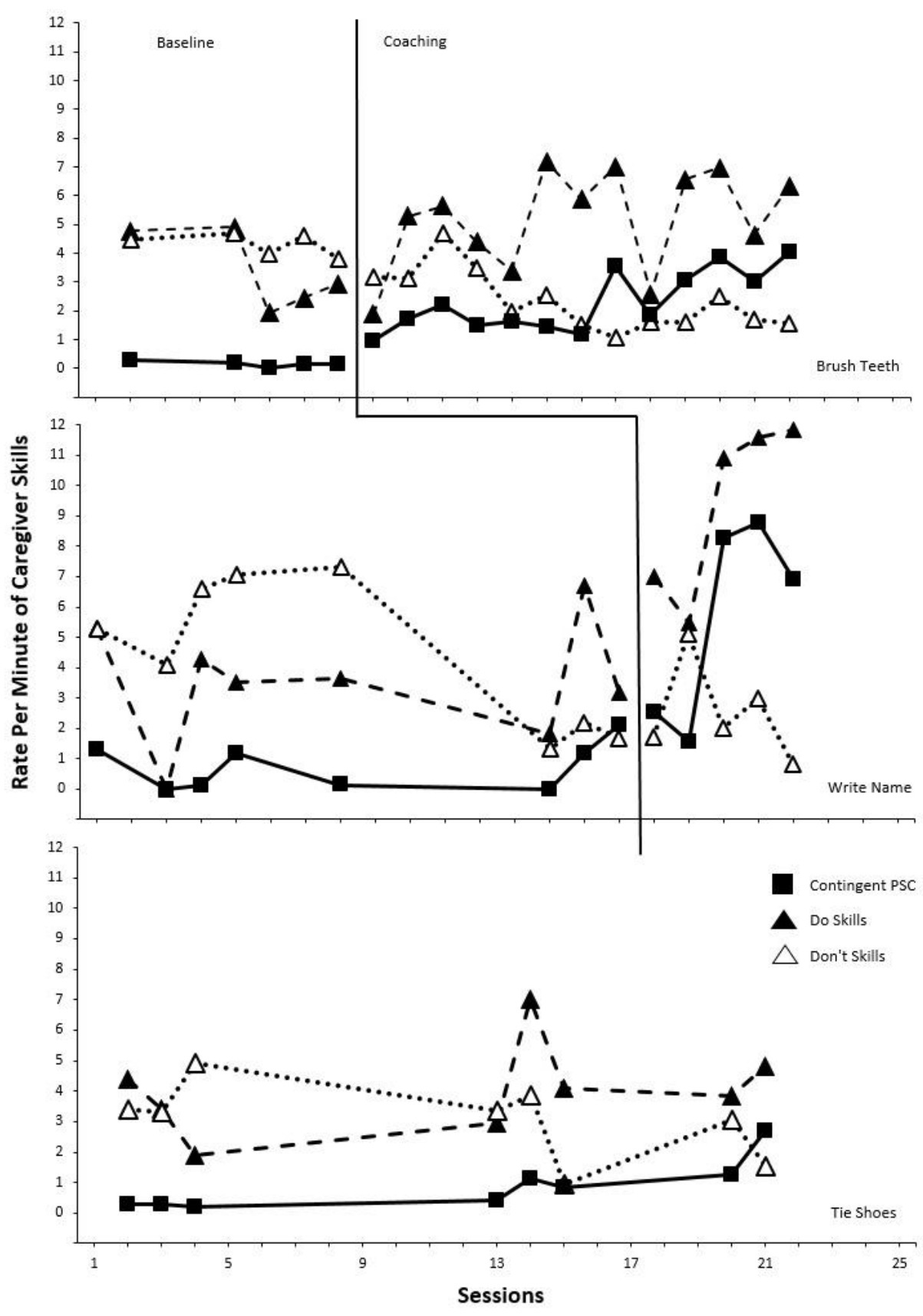

Figure 2 shows the rate of caregiver responding during baseline and intervention phases across three client functional tasks. The rate of the caregiver's use of contingent positive social consequences (PSC), overall rate of "Do Skills" and overall rate of "Don't Skills" is shown. 
Figure 3.

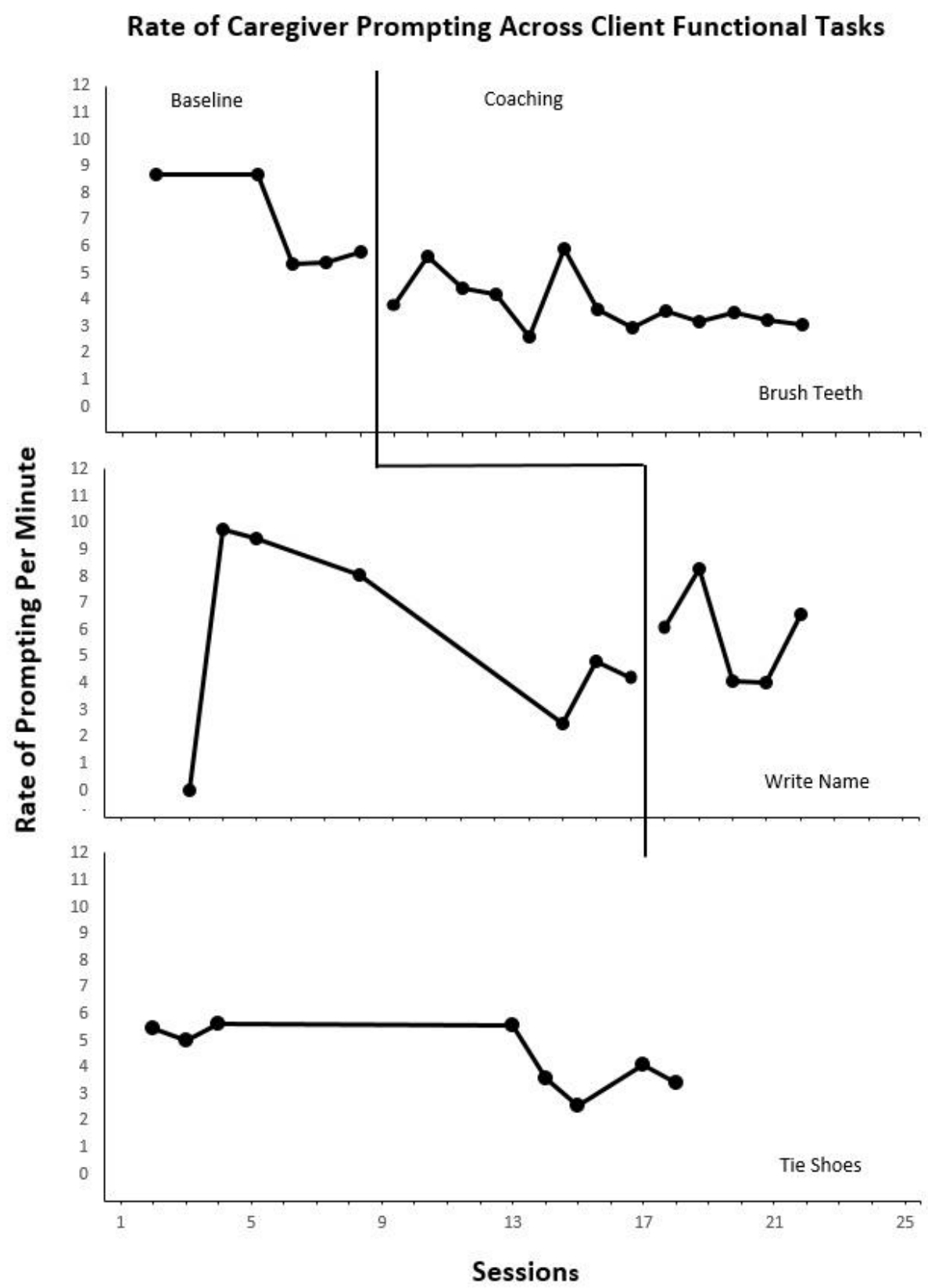

Figure 3 illustrates the caregiver's overall rate of prompting (both correct and incorrect prompt sequences) across three client functional tasks. 
Figure 4.

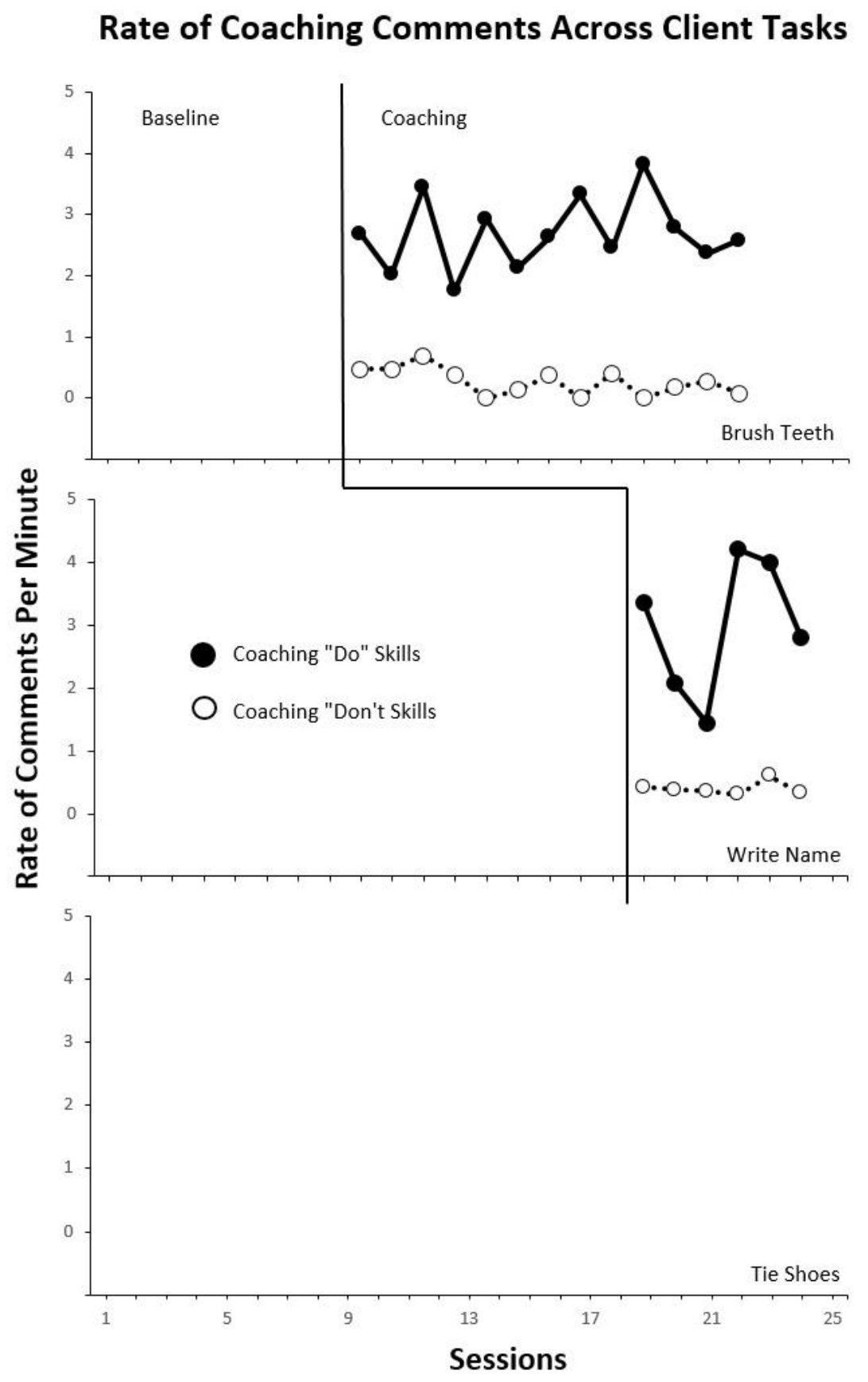

Figure 4 shows the overall rate of coaching "Do Skills" as compared to the overall rate of coaching "Don't Skills" for each intervention session across three client functional tasks. 


\section{Appendix A.}

\section{Client Data Sheet}

\section{Behavior Chain: Brush Teeth}

Date:

Video Time Stamp:

Duration:

Client ID:
Observer:

Primary / Secondary (circle one)

Baseline / Intervention (circle one)

\begin{tabular}{|l|l|l|l|}
\hline \multicolumn{1}{|c|}{ Task Step } & I & P & Not \\
\hline Get toothbrush and paste & & & \\
\hline Open tube and put paste on brush & & & \\
\hline Put cap back on toothpaste & & & \\
\hline Run under water / get wet & & & \\
\hline Brush right side OUT 5 sec & & & \\
\hline Brush left side OUT 5 sec & & & \\
\hline Brush front OUT 5 sec & & & \\
\hline Brush inside TOP right 5 sec & & & \\
\hline \multicolumn{1}{|c|}{ Inside BOTTOM right 5 sec } & & & \\
\hline Brush inside TOP left 5 sec & & & \\
\hline \multicolumn{1}{|c|}{ Inside BOTTOM left 5 sec } & & & \\
\hline Brush inside TOP front 5 sec & & & \\
\hline \multicolumn{1}{|c|}{ Inside BOTTOM 5 sec } & & & \\
\hline Brush tongue & & & \\
\hline Rinse toothbrush & & & \\
\hline Rinse mouth & & & \\
\hline Wash out sink & & & \\
\hline Turn off water & & & \\
\hline Dry face and hands & & & \\
\hline Total Number & & & \\
\hline Completed & & & \\
\hline
\end{tabular}




\section{Appendix B.}

\section{Client Data Sheet}

\section{Behavior Chain: Write First Name (*pseudonym used below)}

Date:

Video Time Stamp: to Duration:

Client ID:
Observer:

Primary / Secondary (circle one)

Baseline / Intervention (circle one)

\begin{tabular}{|l|l|l|l|}
\hline \multicolumn{1}{|c|}{ Task Step } & I & P & Not \\
\hline Pick up pen/pencil/marker/etc. & & & \\
\hline I & & & \\
\hline 八 & & & \\
\hline A & & & \\
\hline I & & & \\
\hline V & & & \\
\hline I & & & \\
\hline I & & & \\
\hline n & & & \\
\hline & & & \\
\hline & & & \\
\hline & & & \\
\hline & & & \\
\hline & & & \\
\hline & & & \\
\hline & & & \\
\hline Total Number & & & \\
\hline \% Completed & & & \\
\hline
\end{tabular}




\section{Appendix C.}

\section{Client Data Sheet}

\section{Behavior Chain: Tie Shoes}

Date:

Video Time Stamp: Duration:

Client ID:
Observer:

Primary / Secondary (circle one) Baseline / Intervention (circle one)

\begin{tabular}{|l|l|l|l|}
\hline \multicolumn{1}{|c|}{ Task Step } & I & P & Not \\
\hline Put shoe on foot & & & \\
\hline Pull laces tight & & & \\
\hline Criss-cross & & & \\
\hline 1 lace under the criss-cross & & & \\
\hline Pull tight & & & \\
\hline Make bunny ear 1 & & & \\
\hline Wrap 2 around bunny ear & & & \\
\hline "jump through the bunny hole" & & & \\
\hline Pull tight & & & \\
\hline & & & \\
\hline & & & \\
\hline & & & \\
\hline & & & \\
\hline & & & \\
\hline & & & \\
\hline & & & \\
\hline Total Number Completed & & & \\
\hline
\end{tabular}




\section{Appendix D.}

\section{Caregiver Skills Data Sheet}

Date:

Video Time Stamp: to

Duration:

Caregiver ID:
Observer:

Primary / Secondary (circle) Baseline / Intervention (circle) Task:

DO SKILLS

\begin{tabular}{|l|l|l|}
\hline Correct Use of Commands/Prompts & Tallies & Total \\
\hline Initiating Command Sequence & & \\
\hline Verbal Prompt Sequence & & \\
\hline Visual Prompt Sequence & & \\
\hline Physical Prompt Sequence & & \\
\hline Total Correct Commands/Prompts & & \\
\hline
\end{tabular}

\begin{tabular}{|l|l|l|l|}
\hline Positive Social Consequences & Contingent & Non-contingent & Total \\
\hline Labeled Praise & & & \\
\hline Unlabeled Praise & & & \\
\hline Reflection & & & \\
\hline Behavior Description & & & \\
\hline Physical Touch & & & \\
\hline Total Positive Social Consequences & & & \\
\hline
\end{tabular}

\begin{tabular}{|l|l|l|}
\hline Other & & \\
\hline Planned Ignoring & & \\
\hline Total Do Skills & & \\
\hline \multicolumn{2}{|c}{ IOA "DO" } \\
\hline
\end{tabular}

Don't Skills

\begin{tabular}{|l|l|l|}
\hline Incorrect Command / Prompt Sequences & Tallies & Total \\
\hline Questions & & \\
\hline Indirect Commands & & \\
\hline Incorrect Timing & & \\
\hline Total Incorrect Sequences & & \\
\hline
\end{tabular}

\begin{tabular}{|l|l|l|}
\hline Negative Social Consequences & & \\
\hline Negative Talk & & \\
\hline Negative Touch & & \\
\hline Total Don't Skills & & \\
\hline
\end{tabular}

Rate of Do Skills (\#/duration): Rate of Don't Skills (\#/duration): Rate of Prompting (\#/duration): Rate of Contingent PSC (\#/duration):

Appendix E.

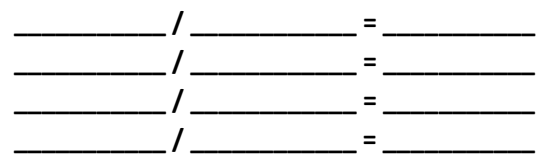




\section{Coaching Data Sheet}

Date:

Observer:

Video Time Stamp: to primary secondary

Duration:

Task:

\section{DO SKILLS}

\begin{tabular}{|l|l|}
\hline Labeled Praise $\mathbf{1}$ & \\
For LP/RF/BD/PT & \\
\hline Labeled Praise $\mathbf{2}$ & \\
For other positive UP/ enthusiasm/ imitation & \\
\hline $\begin{array}{l}\text { Labeled Praise } \mathbf{3} \\
\text { Coach provides a positive evaluation of the caregiver closing } \\
\text { the loop }\end{array}$ & \\
\hline $\begin{array}{l}\text { Labeled Praise } \mathbf{4} \\
\text { Coach provides praise for use of specific skills training (i.e., } \\
\text { chaining, prompting, modeling, physical guidance, fading) }\end{array}$ & \\
\hline Unlabeled Praise & \\
\hline $\begin{array}{l}\text { Descriptive Label } \\
\text { (That was a question; that was unlabeled praise; that was an } \\
\text { indirect command) }\end{array}$ & \\
\hline $\begin{array}{l}\text { Direct Command } \\
\text { (Describe what he is doing, prompting for skills, telling } \\
\text { caregiver exact word to say) }\end{array}$ & \\
\hline $\begin{array}{l}\text { Higher Order } \\
\text { (General evaluative statements: your prompts are helping him } \\
\text { complete the steps, good timing, etc.) }\end{array}$ & \\
\hline
\end{tabular}

\section{DON'T SKILLS}

\begin{tabular}{|l|l|}
\hline $\begin{array}{l}\text { Indirect Command } \\
\text { (Could you be more specific, Let's try counting...) }\end{array}$ & \\
\hline $\begin{array}{l}\text { Critical Statement } \\
\text { (Stop giving commands, don't ask so many questions) }\end{array}$ & \\
\hline $\begin{array}{l}\text { Incorrect statement } \\
\text { (mislabeling target behavior; praising a “don't skill”) }\end{array}$ & \\
\hline
\end{tabular}

Adapted from Stokes, Barkaia, Rossi, Studivant, \& Budd - JMU/DePaul TCIT (2014) (adapted from Chase, 2011 PCIT conference presentation). 


\section{Appendix F.}

\section{Social Validity Questionnaire}

Name:

Date:

\begin{tabular}{|l|l|l|l|c|c|}
\hline Question for Caregiver & Agree & $\begin{array}{c}\text { Somewhat } \\
\text { Agree }\end{array}$ & Neutral & $\begin{array}{c}\text { Somewhat } \\
\text { Disagree }\end{array}$ & Disagree \\
\hline $\begin{array}{l}\text { Using the communications } \\
\text { technology during the } \\
\text { intervention was } \\
\text { comfortable for me. }\end{array}$ & 1 & 2 & 3 & 4 & 5 \\
\hline $\begin{array}{l}\text { Coaching comments were } \\
\text { easily heard and understood } \\
\text { through the headset. }\end{array}$ & & & & & \\
\hline $\begin{array}{l}\text { I will recommend the same } \\
\text { communications technology } \\
\text { for distance coaching if this } \\
\text { study is replicated. }\end{array}$ & & & & & \\
\hline $\begin{array}{l}\text { I found the training to be } \\
\text { useful. }\end{array}$ & & & & & \\
\hline $\begin{array}{l}\text { I use the skills I learned } \\
\text { outside of coaching } \\
\text { sessions. }\end{array}$ & & & & & \\
\hline $\begin{array}{l}\text { I will recommend the } \\
\text { training to others caregivers, } \\
\text { parents or therapists who } \\
\text { work with children or adults } \\
\text { with brain injuries. }\end{array}$ & & & & & \\
\hline $\begin{array}{l}\text { The training met my } \\
\text { expectations. }\end{array}$ & & & & & \\
\hline $\begin{array}{l}\text { The researcher-coach was } \\
\text { responsive to my needs. }\end{array}$ & & & & & \\
\hline
\end{tabular}

Adapted from Barkaia, Stokes, \& Mikiashvili (2016). 


\section{References}

Arco, L. \& Bishop, J. (2009). Single participant studies in positive behavior support for parents of individuals with brain injuries. Brain Impairment, 10(3), 307-319.

Baer, D.M., Wolf, M.M., \& Risley, T.R. (1968). Some current dimensions of applied behavior analysis. Journal of Applied Behavior Analysis, 1(1), 91-97.

Barkaia, A. \& Stokes, T.F. (2015). Frequency and content of coaching in Teacher-Child Interaction Training (TCIT). Poster presentation. Virginia Association of Behavior Analysis. Charlottesville, VA.

Barkaia, A., Stokes, T.F., \& Mikiashvili, T. (2016, May). International telehealth coaching of therapists to enhance verbalizations of children with autism. Poster accepted for presentation at Association for Behavior Analysis International Conference, Chicago, IL.

Barretto, A., Wacker, D., Harding, J., Lee, J., \& Berg, W. (2006). Using telemedicine to conduct behavioral assessments. Journal of Applied Behavior Analysis, 39(3), 333-340.

Barnett, M., Niec, L., Peer, S., Jent, J., Weinstein, A., Gisbert, P. \& Simpson, G. (2015). Successful therapist-parent coaching: How in vivo feedback relates to parent engagement in Parent-Child Interaction Therapy. Journal of Clinical Child \& Adolescent Psychology, DOI: 10.1080/15374416.2015.1063428.

Billmire, M.E. \& Myers, P.A. (1985). Serious head injury in infants: Accident or abuse?, Pediatrics, 75(2), 340-342. 
Brown, F., Whittingham, K., Boyd, R., \& Sofronoff, K. (2013). A systematic review of parenting interventions for traumatic brain injury: Child and parent outcomes. Journal of Head Trauma Rehabilitation, 28(5), 349-360.

Brown, R. (2012). Training and assessment of toothbrushing skills among children with special needs. Master's thesis.

Catania, A. C. (2013) Learning ( $5^{\text {th }}$ ed.). Cornwall on Hudson, NY: Sloan Publishing. Centers for Disease Control and Prevention. (2015). Report to Congress on Traumatic Brain Injury in the United States: Epidemiology and Prevention. National Center for Injury Prevention and Control; Division of Unintentional Injury Prevention. Atlanta, GA.

Corrigan, P. \& Bach, P. (2005). Behavioral treatment. In Silver, J., McAllister, T., \& Yudofsky, S. (Eds.) Textbook of Traumatic Brain Injury. 661-678. Arlington, VA: American Psychiatric Publishing.

Choate, M., Pincus, D., Eyberg, S., \& Barlow, D. (2005). Parent-Child Interaction Therapy for treatment of separation anxiety in young children: A pilot study. Cognitive and Behavioral Practice, 12(1), 126-135.

Cooper, M., Thomson, C. \& Baer, D. (1970). The experimental modification of teacher attending behavior. Journal of Applied Behavior Analysis, 3, 153-157.

Crimmins, D., Bradlyn, A. Lawrence, J., \& Kelly, J. (1984). A training technique for improving the parent-child interaction skills of an abusive-neglectful mother. Child Abuse \& Neglect, 8, 533-539. 
Cuvo, A. (1979). Multiple-baseline design in instructional research: Pitfalls of measurement and procedural advantages. American Journal of Mental Deficiency, 84(3), 219-228.

Ducharme, J. \& Feldman, M. (1992). Comparison of staff training strategies to promote generalized teaching skills. Journal of Applied Behavior Analysis, 25(1), 165-179.

Ducharme, J., \& Spencer, T. (2001). Training brain injury rehabilitation therapists to use generalized teaching and interaction skills. Brain Injury, 15(4), 333-347.

Eyberg, S., \& Funderburk, B. (2011). Parent-child Interaction Therapy Protocol. PCIT International, Inc.

Feeney, T.J. (2010). There's always something that works: Principles and practices of positive behavior support for individuals with traumatic brain injury and problem behaviors. Seminars in Speech and Language, 31(3), 145-161.

Forducey, P., Ruwe, W., Dawson, S. Scheideman-Miller, C., McDonald, N., \& Hantla, M. (2003). Using telerehabilitation to promote TBI recovery and transfer of knowledge. NeuroRehabilitation, 18, 103-111.

Frieder, J., Peterson, S., Woodward, J., Crane, J., Garner, M. (2009). Teleconsultation in school settings: Linking classroom teachers and behavior analysts through webbased technology. Behavior Analysis in Practice, 2(2), 32-39.

Garcia, D., Hungerford, G. \& Bagner, D. (2014). Topical review: Negative behavioral and cognitive outcomes following traumatic brain injury in early childhood. Journal of Pediatric Psychology, 40(4), 391-397. 
Gianoumis, S., \& Sturmey, P. (2012). Generalization procedures in training interventionists for individuals with developmental disabilities. Behavior Modification, 36(5), 619-629.

Guercio, J., \& Dixon, M. (2011). The observer effect and its impact on staff behavior in an acquired brain injury neurobehavioral treatment setting. Journal of Organizational Behavior Management, 31(1), 43-54.

Hegel, M. \& Ferguson, R. (2000). Differential reinforcement of other behavior (DRO) to reduce aggressive behavior following traumatic brain injury. Behavior Modification, 24(1), 94-101.

Heinicke, M. \& Carr, J. (2014). Applied behavior analysis in acquired brain injury rehabilitation: A meta-analysis of single-case intervention research. Behavioral Interventions, 29, 77-105.

Heitzman-Powell, L., Buzhardt, J., Rusinko, L., \& Miller, T. (2014). Formative evaluation of an ABA outreach training program for parents of children with autism in remote areas. Focus on Autism and Other Developmental Disabilities, 29(1), 23-38.

Herbert, E. \& Baer, D. (1972). Training parents as behavior modifiers: self-recording of contingent attention. Journal of Applied Behavior Analysis, 5(2), 139-149.

Herrnstein, R. J. (1970). On the law of effect. Journal of the Experimental Analysis of Behavior, 13, 243-266.

Hoofien, D., Gilboa, A., Vakil, E., \& Donovick, P. (2001). Traumatic brain injury (TBI) 10-20 years later: a comprehensive outcome study of psychiatric symptomology, cognitive abilities and psychosocial functioning. Brain Injury, 15(3), 189-209. 
Horner, R.D. \& Baer, D.M. (1978). Multiple-probe technique: a variation of the multiple baseline. Journal of Applied Behavior Analysis, 11(1), 189-196.

Jacobs, H. (2010) Understanding Everybody’s Behavior After Head Injury: Don't “Don't!” Wake Forest, North Carolina: Lash and Associations Publishing/Training.

Junque, C., Bruna, O. \& Mataro, M. (1997). Information needs of the traumatic brain injury patient's family members regarding the consequences of the injury and associated perception of physical, cognitive, emotional and quality of life changes. Brain Injury, 11(4), 251-258.

Keenan, H.T., Runyan, D.K., Marshall, S.W., Nocera, M.A., Merten, D.F., \& Sinal, S.H. (2003). A population-based study of inflicted traumatic brain injury in young children. Journal of American Medical Association, 290(5), 621-626.

Koegel, R., Russo, D., \& Rincover, A. (1977). Assessing and training teachers in the generalized use of behavior modification with autistic children. Journal of Applied Behavior Analysis, 10, 197-205.

Kolakowsky-Hayner, S., Miner, K., \& Kreutzer, J. (2001). Long-term life quality and family needs after traumatic brain injury. Journal of Head Trauma Rehabilitation, 16(4), 374-385.

Kraus, J. \& Chu, L. (2005) Epidemiology. In Silver, J., McAllister, T., and Yudofsky, S. (Eds.) Textbook of Traumatic Brain Injury. 3-26. Arlington, VA: American Psychiatric Publishing.

Lash, M. (ed.). (2007). The Essential Brain Injury Guide $\left(4^{\text {th }}\right.$ ed). American Academy for the Certification of Brain Injury Specialists. Brain Injury Association of America. 
Lyon, A., Gersenson, R., Farahmand, F., Thaxter, P., Behling, S., \& Budd, K. (2009). Effectiveness of Teacher-Child Interaction Training (TCIT) in a preschool setting. Behavior Modification, 33(6), 855-884.

Masel, B.E. \& DeWitt, D.S. (2010). Traumatic brain injury: A disease process, not an event. Journal of Neurotrauma, 27, 1529-1540.

Meixner, C., O’Donoghue, C.R., \& Witt, M.R. (2013). Accessing crisis intervention services after brain injury: A mixed methods study. Rehabilitation Psychology, $58(4), 377-385$.

McDowell, J. J. (1988). Matching theory in natural human environments. The Behavior Analyst, 11, 95-109.

McMorrow, M. (2005). The Helping Exchange: P.E.A.R.L. Youngsville, NC: Lash \& Associates Publishing/Training Inc.

Mickelwright, J., King, T., O’Toole, K., Henrich, C., \& Floyd, F. (2012). Parental distress, parenting practices, and child adaptive outcomes following traumatic brain injury. Journal of the International Neuropsychological Society, 18, 343350.

Mozzoni, M., \& Baily, J. (1996). Improving training methods in brain injury rehabilitation. Journal of Head Trauma Rehabilitation, 11(1), 1-17.

Mozzoni, M.P. \& Hartnedy, S. (2000). Escape and avoidance hypothesis testing using an alternating treatments design. Behavioral Interventions, 15, 269-277.

Naik-Polan, A., \& Budd, K. (2008). Stimulus generalization of parenting skills during Parent-Child Interaction Therapy. Journal of Early and Intensive Behavior Intervention, 5(3), 71-92. 
National Association of State Head Injury Administrators (NASHIA). (2006).

Neurobehavioral Issues of Traumatic Brain Injury: An Introduction. Bethesda, MD.

Palmisano, B. \& Arco, L. (2007). Changes in functional behavior of adults with brain injury and spouse-caregiver burden with in-home neurobehavioral intervention. Behaviour Change, 24(1), 36-49.

Parsonson, B.S., Baer, A.M., \& Baer, D.M. (1974). The application of generalized correct social contingencies: An evaluation of a training program. Journal of Applied Behavior Analysis, 7, 427-437.

Peterson, C., Xu, L., Florence, C., Parks, S.E., Miller, T.R., Barr, R.G., Barr, M. \& Steinbeigle, R. (2014). The medical cost of abusive head trauma in the United States. Pediatrics, 134(1), 91-99.

Peters, M., Gluck, M. \& McCormick, M. (1992). Behaviour rehabilitation of the challenging client in less restrictive settings. Brain Injury, 6(4), 299-314.

Potter, J., Wade, S., Walz, N., Cassedy, A., Yeates, K., Stevens, M., \&Taylor, H. (2011). Parenting style is related to executive dysfunction after brain injury in children. Rehabilitation Psychology, 56(4), 351-358.

Rahman, B., Oliver, C. \& Alderman, N. (2010). Descriptive analysis of challenging behaviors shown by adults with acquired brain injury. Neuropsychological Rehabilitation, 20(2), 212-238.

Ricker, J., Rosenthal, M., Garay, E., DeLuca, J., Germain, A., Abraham-Fuchs, K., \& Schmidt, K. (2002). Telerehabilitation needs: A survey of persons with acquired brain injury. Journal of Head Trauma Rehabilitation, 17(3), 242-250. 
Sanders, M. \& Glynn, T. (1981). Training parents in behavioral self-management: An analysis of generalization and maintenance. Journal of Applied Behavior Analysis, 14(3), 223-237.

Shanley, J. \& Niec, L. (2010). Coaching parents to change: The impact of in vivo feedback on parents' acquisition of skills. Journal of Clinical Child and Adolescent Psychology, 39(2), 282-287.

Sherer, M., Novack, T., Sander, A., Struchen, M., Alderson, A., \& Thompson, R. (2002). Neuropsychological assessment and employment outcome after traumatic brain injury: A review. The Clinical Neuropsychologist, 16(2), 157-178.

Sherer, M., Sander, A., Nick, T., Melguizo, M., Tulsky, D., Kisala, P., Hanks, R., \& Novack, T. (2015). Key dimensions of impairment, self-report, and environmental supports in persons with traumatic brain injury. Rehabilitation Psychology, 60(2), 138-146.

Schopp, L, Johnstone, B., \& Reid-Arndt, S. (2005). Telehealth brain injury training for rural behavioral health generalists: Supporting and enhancing rural service delivery networks. Professional Psychology: Research and Practice, 36(2), 158163.

Stokes, T.F. (1992). Discrimination and generalization. Journal of Applied Behavior Analysis, 25, 429-432.

Stokes, T.F. \& Baer, D.M. (1977). An implicit technology of generalization. Journal of Applied Behavior Analysis, 10(2), 349-367.

Stokes, T.F. \& Osnes, P. (1989). An operant pursuit of generalization. Behavior Therapy, $20,337-355$. 
Studivant, K. (2015). A detailed analysis of coaching in Teacher-Child Interaction Training (TCIT). (Doctoral dissertation). Retrieved from Dissertations. (36).

VSee (n.d.). Retrieved March 30, 2016 from VSee: https://vsee.com/blog/hipaa.

Wacker, D., Lee, J., Dalmau, Y., Kopelman, T., Lindgren, S., Kuhle, J., Pelzel, K., Dyson, S., Schieltz, K., \& Waldron, D. (2013). Conducting functional communication training via telehealth to reduce the problem behavior of young children with autism. Journal of Physical Disabilities, 25, 35-48.

Wade, S., Cassedy, A., Walz, N., Stancin, T. Taylor, H., \& Yeates, K. (2011). The relationship of parental warm responsiveness and negativity to emerging behavior problems following traumatic brain injury in young children. Developmental Psychology, 47(1), 119-133.

WPA2. (n.d.). Retrieved March 30, 2016 from Webopedia: http://www.webopedia.com/TERM/W/WPA2.html.

Wolf, M.M. (1978). Social validity: The case for subjective measurement or how applied behavior analysis is finding its heart. Journal of Applied Behavior Analysis, 11(2), 203-214.

Wood, R. \& Alderman, N. (2011). Applications of operant learning theory to the management of challenging behavior after traumatic brain injury. Journal of Head Trauma Rehabilitation, 26(3), 202-211.

Ylvisaker, M., Turkstra, L., \& Coelho, C. (2005). Behavioral and social interventions for individuals with traumatic brain injury: A summary of the research with clinical applications. Seminars in Speech and Language, 26(4), 256-267. 